\title{
Mediators of invasions in the sea: life history strategies and dispersal vectors facilitating global sea anemone introductions
}

\author{
Heather Glon (1) - Marymegan Daly (1) - James T. Carlton (1) - Megan M. Flenniken • \\ Zara Currimjee
}

Received: 21 December 2019/Accepted: 20 July 2020/Published online: 16 August 2020

(C) Springer Nature Switzerland AG 2020

\begin{abstract}
Widespread non-native species tend to demonstrate an apparent lack of selectivity in habitat requirements, feeding regimes, and reproductive needs, while displaying a tendency to thrive in human-modified habitats. The high phenotypic plasticity typical of sessile, substrate-attached marine species may enhance their chances of survival and spread in a new region. Anthropogenic activities have changed marine habitats over a wide range of phenomena, including water temperature, community species composition, and the types of available substrates, creating new physical and biotic regimes that may contribute to the potential for successful species introduction. Here we examine ten species of sea anemones that have been introduced outside of their native range, and elucidate specific characteristics that are common among globally introduced sea anemones. Various life history strategies enable these
\end{abstract}

H. Glon $(\bowtie) \cdot$ M. Daly

Department of Evolution, Ecology, and Organismal

Biology, Ohio State University, Columbus,

$\mathrm{OH}$ 43212, USA

e-mail: Glon.2@osu.edu

J. T. Carlton · Z. Currimjee

Williams College - Mystic Seaport Maritime Studies

Program, 75 Greenmanville Ave, Mystic,

CT 06355, USA

M. M. Flenniken

Department of Ecology and Evolution, Stony Brook

University, Stony Brook, NY 11794, USA species to survive and flourish through transport, introduction, establishment and spread, leading to the successful colonization of a new geographic area. Considering life history strategies and weighing of vector potential, we suggest conditions that facilitate introduction of these species, and identify species of sea anemones that may be introduced in the future in the face of changing climate and increased anthropogenic activities.

Keywords Sea anemone $\cdot$ Cnidaria $\cdot$ Actiniaria Introduced species · Vector

\section{Introduction}

Marine biological invasions are being amplified by increasing anthropogenic dispersal and environmental alterations, including stressed habitats and climate change. Anthropogenic activities have enabled linkages of donor regions with new recipient regions that may not otherwise be connected, overcoming natural barriers which may have long kept many regions isolated (Carlton 1996; Ruiz et al. 1997). High-latitude regions are experiencing the poleward expansion of many species in the face of warming ocean temperatures (Jurgens 2018).

Biological invasions may proceed through four basic stages (Blackburn et al. 2011): Transport, Introduction, Establishment, and Spread (Fig. 1). At 


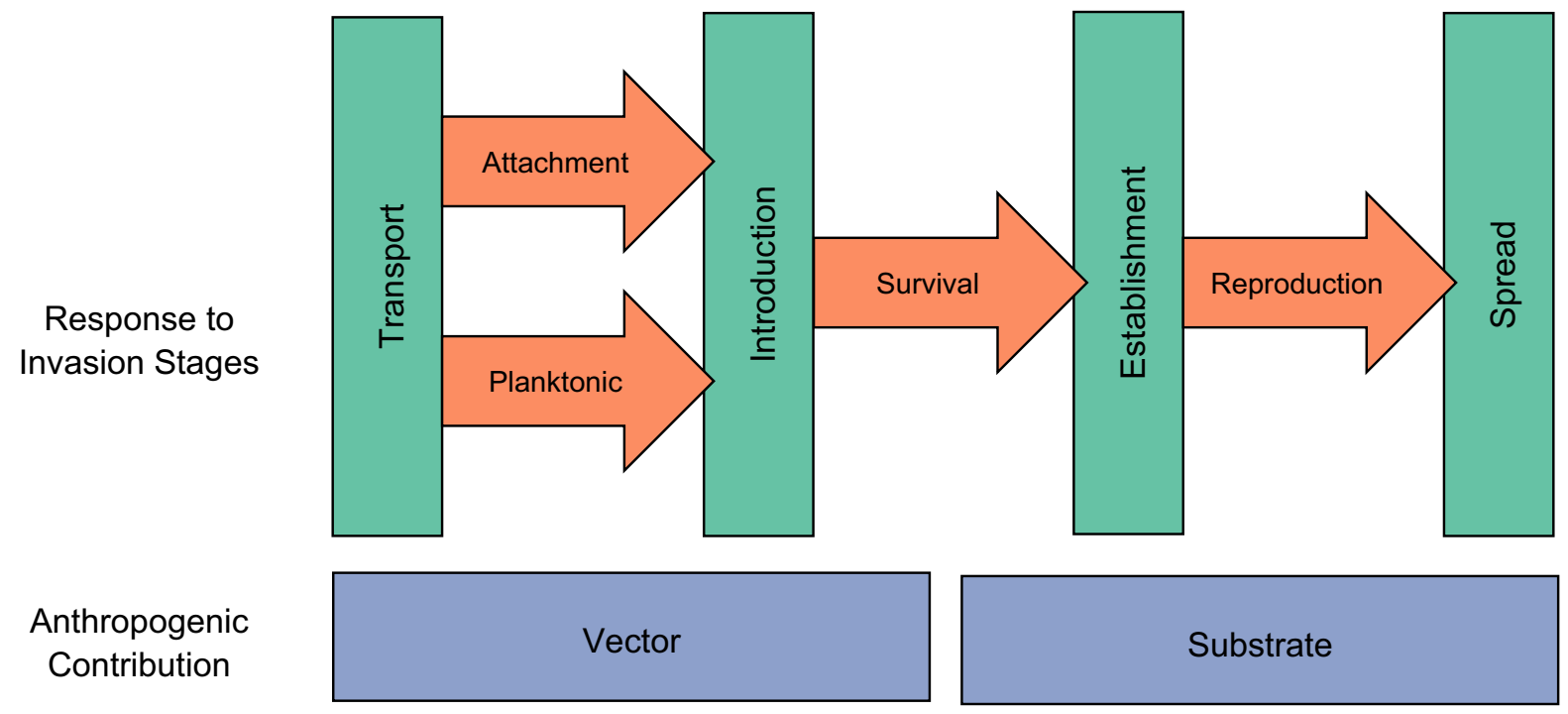

Fig. 1 Stages of invasion adapted from Blackburn et al. (2011), including the associated biological responses as well as where anthropogenic contributions may facilitate invasions

each of these invasion stages a species may exhibit different characteristics or strategies due to changing transport or environmental conditions or interactions with members of the invaded communities (Lodge 1993; Blackburn et al. 2011). Additionally, human activities may influence the potential for a species to pass to the next stage, either by providing a transport vector or by creating new suitable habitat.

Certain species within given taxonomic groups are more likely to be candidates for successful introduction based on their ecological and biological traits. Within the actiniarian sea anemones, there is an amazing array of life history strategies regulating reproduction, dispersal, and tolerance to abiotic factors such as temperature and salinity (Shick 1991). A general predisposition among many anemone species towards hardiness and potentially rapid proliferation creates a group well-adapted for introduction.

Here we address how life history strategies and dispersal vectors impact the success and history of marine invasions, using sea anemone species as models of introduction across the world. Sea anemone invasions leverage multiple anthropogenic activities and are inferred to span timescales from historical (pre-1900) to recent (and ongoing). Our goal is to consolidate our current understanding of examples of anemone invasions while highlighting and comparing the intersection of life history and ecological strategies and modes of introductions. This synthesis thus provides a baseline to predict future effects and risks of human-mediated dispersal of sea anemones.

\section{Species}

We consider here ten species of sea anemones that are globally known as introduced throughout the world. Eight species belong to the Acuticulata clade of the superfamily Metridioidea, one species is in the superfamily Actinoidea, and one is in the superfamily Edwardsioidea. The ten species are presented in an

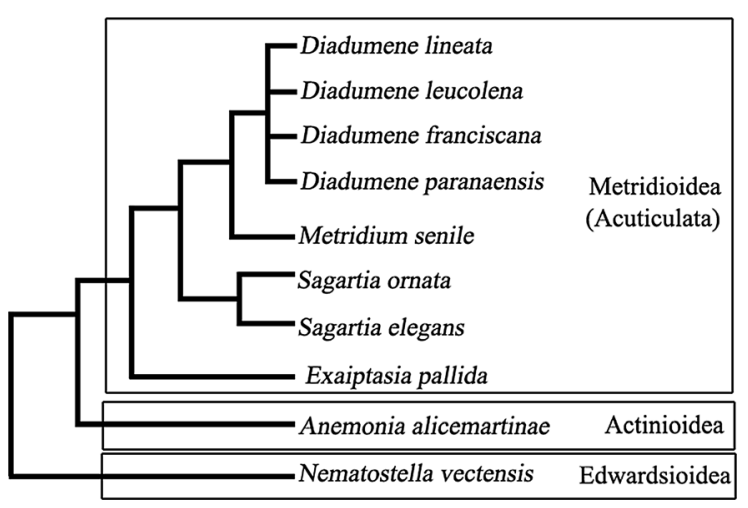

Fig. 2 Current understanding of the phylogenetic relationships of the ten species or purported species included in this review, based primarily on Rodríguez et al. (2014), with the major clades to which each belongs highlighted 
order that reflects our current understanding of their phylogenetic relationships (Figs. 2, 3; see Rodríguez et al. 2014). Several of these species (Diadumene lineata, Exaiptasia pallida, Metridium senile, and Nematostella vectensis) have been well studied, while others are less well known or only recently described. Sea anemones have a reputation for being difficult to identify, and thus are historically overlooked in surveys and are prone to misidentification, thus these species serve as a starting point in our understanding of sea anemone introductions. Our focus is on the life history traits and biology (Table 1) that may regulate introduction, with notes on their native and introduced ranges, rather than a complete review of the introduction history of each species, particularly as there may be cryptic diversity present within some introduced ranges. In addition, we consider several additional species whose potential introduction histories remain to be determined.

\section{Diadumene lineata (Verrill, 1869)}

Diadumene lineata (previously known as Haliplanella luciae (Verrill, 1898)) is the most widely distributed
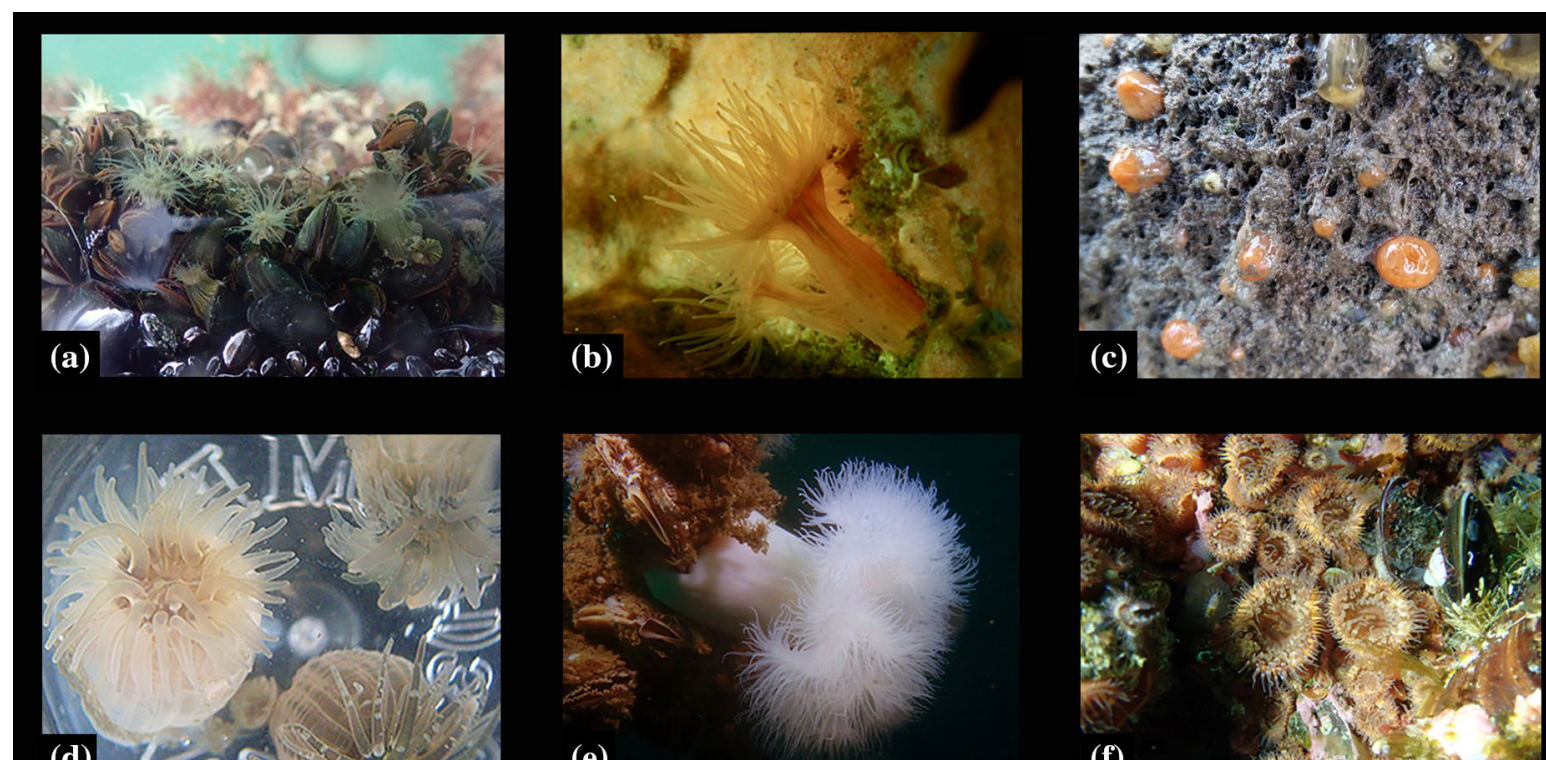

(e)
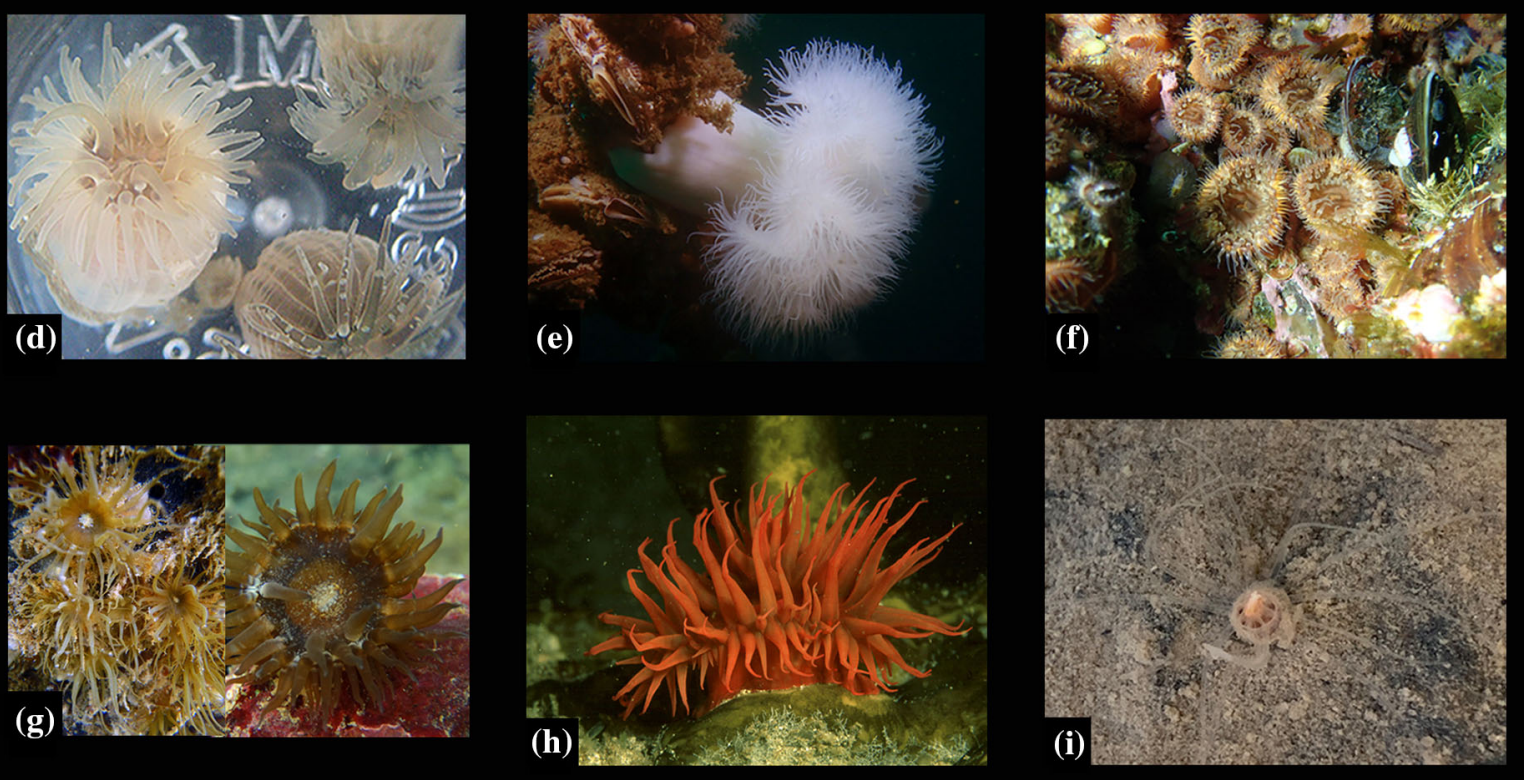

Fig. 3 Photographs of sea anemone species with notable introduction events: a Diadumene lineata (Photo: Heather Glon, Nova Scotia, Canada, 2018); b Diadumene leucolena (Photo: Heather Glon, Cape Cod, Massachusetts, 2018); c Diadumene franciscana (Photo: used with permission from Damon Tighe, California, 2015); d Diadumene paranaensis (Photo: used with permission from Sérgio Stamper, Brazil, 2010); e Metridium senile (Photo: Heather Glon, Iceland, 2019); f Sagartia elegans
(Photo: Heather Glon, Norway, 2018); g Exaiptasia pallida (Photo: used with permission from Alejandro Grajales, Sea of Cortez \& Hawaii, 2012) h Anemonia alicemartinae (Photo: used with permission from Vreni Häussermann, Chile, 2001); i Nematostella vectensis (Photo: used with permission by Whitney Leach, Massachusetts, 2016) (Not pictured: Sagartia elegans; see cover of Biological Bulletin December 2019 (volume 237, number 3 ) for color photo) 
Table 1 Summary of the habitat and life history traits for each of the species included in this review

\begin{tabular}{|c|c|c|c|c|c|}
\hline Species & $\begin{array}{l}\text { Reproduction } \\
\text { type } \\
\text { Introduced range }\end{array}$ & $\begin{array}{l}\text { Depth } \\
\text { Native and introduced }\end{array}$ & $\begin{array}{l}\text { Substrate } \\
\text { type } \\
\text { nges }\end{array}$ & $\begin{array}{l}\text { Temperature } \\
\text { tolerance }\end{array}$ & $\begin{array}{l}\text { Salinity } \\
\text { tolerance }\end{array}$ \\
\hline Diadumene lineata & Asexual (both?) & Intertidal, shallow & $\begin{array}{l}\text { Hard and } \\
\text { Soft }\end{array}$ & Broad & Broad \\
\hline Diadumene leucolena & Sexual & Shallow & Hard & Medium & Broad \\
\hline Diadumene franciscana & Both & Shallow & Hard & Broad & Broad \\
\hline Diadumene paranaensis & Asexual & Shallow & Hard & Medium & Broad \\
\hline Metridium senile & Both & Intertidal to $>100 \mathrm{~m}$ & Hard & Medium & Broad \\
\hline $\begin{array}{l}\text { Sagartia sp. "South } \\
\text { Africa" }\end{array}$ & Parthenogenic & Shallow & Hard & Medium & Broad \\
\hline Sagartia elegans & Both & $\begin{array}{l}\text { Shallow (native to } \\
90 \mathrm{~m} \text { ) }\end{array}$ & Hard & Medium & Medium \\
\hline Exaiptasia pallida & Asexual (both?) & Shallow & Hard & Medium & Broad \\
\hline Anemonia alicemartinae & Asexual & $<25 \mathrm{~m}$ & Hard & Narrow & Narrow \\
\hline Nematostella vectensis & Both & Intertidal & Soft & Broad & Broad \\
\hline
\end{tabular}

Reproduction type refers to the strategy recorded in the introduced range ("both" refers to asexual and sexual strategies). Depth encompasses their most commonly reported depth. Substrate type is the preferred substrate that a species can be found attaching or burrowing into. Tolerance to temperature and salinity extremes is based on our current understanding of adult tolerance throughout native and introduced ranges. Temperature categories: Narrow = restricted to stable temperatures within a single temperature zone; Medium = adapted to a more than one temperature zone; Broad $=$ able to persist extreme temperature swings outside of native range . Salinity categories: Narrow $=$ restricted to full ocean salinity; Medium $=$ adapted to ephemeral salinity fluctuations; Broad $=$ adapted to estuarine and marine conditions

sea anemone in the world and among the most wellstudied of the non-native sea anemones, occurring broadly throughout the northern and southern hemispheres (Fig. 4; Shick 1976; Shick and Lamb 1977; Ting and Geller 2000; Fautin and Hand 2007). A shallow-water species, reaching $3 \mathrm{~cm}$ in height, it is commonly found in the intertidal zone (Fukui 1991) and in shallow subtidal fouling communities (Ting and Geller 2000; Jewett et al. 2005). It is a habitat generalist (Hausman 1919) with individuals found on hard natural substrates such as pebbles, rocks, and oyster shells, on artificial substrates such as docks and piers, and as a common epibiont on other organisms including ascidians, barnacles, sponges, and seaweeds (Uchida 1932; Miyawaki 1951; Sassaman and Mangum 1970; Z. Currimjee and M. Flenniken, personal observations). In certain locations, D. lineata is also a common species on mudflats and in salt marsh sediments, with each individual either loose in a small depression or attached to debris or hard substrate under the mud surface, manifested as a cluster of tentacles at the sediment surface at low tide, but a sea of expanded crowns at high tide (J. T. Carlton, personal observations, 2019, Coos Bay, Oregon).

Diadumene lineata is euryhaline and eurythermal (Miyawaki 1951; Sassaman and Mangum 1970; Shick 1976, 1991; Dunn 1982). It is a well-known estuarine species, characteristic of harbors, bays, and lagoons, where it tolerates salinities as low as $8 \%$ (Podbielski et al. 2016) and survives freshwater conditions for short periods of time (Miyawaki 1951). Notably, the presence of $D$. lineata in the Baltic Sea spans a range of salinities (Podbielski et al. 2016). It is generally not found in hypersaline habitats, suggesting that it is more tolerant of reduced versus elevated salinities. However, populations are most successful near oceanic salinities, and decline in lower salinities as seen by the reduction in feeding, growth and fission between 14 and 24\% (Podbielski et al. 2016; Konecny and Harley 2019; Ryan and Miller 2019). It persists in temperatures from below freezing to $30{ }^{\circ} \mathrm{C}$, and can exist short-term at higher temperatures (Minasian and Mariscal 1979; Ryan 2018). Survival during wide temperature swings, air exposure, and extremely low salinities has equipped the species to endure intertidal 


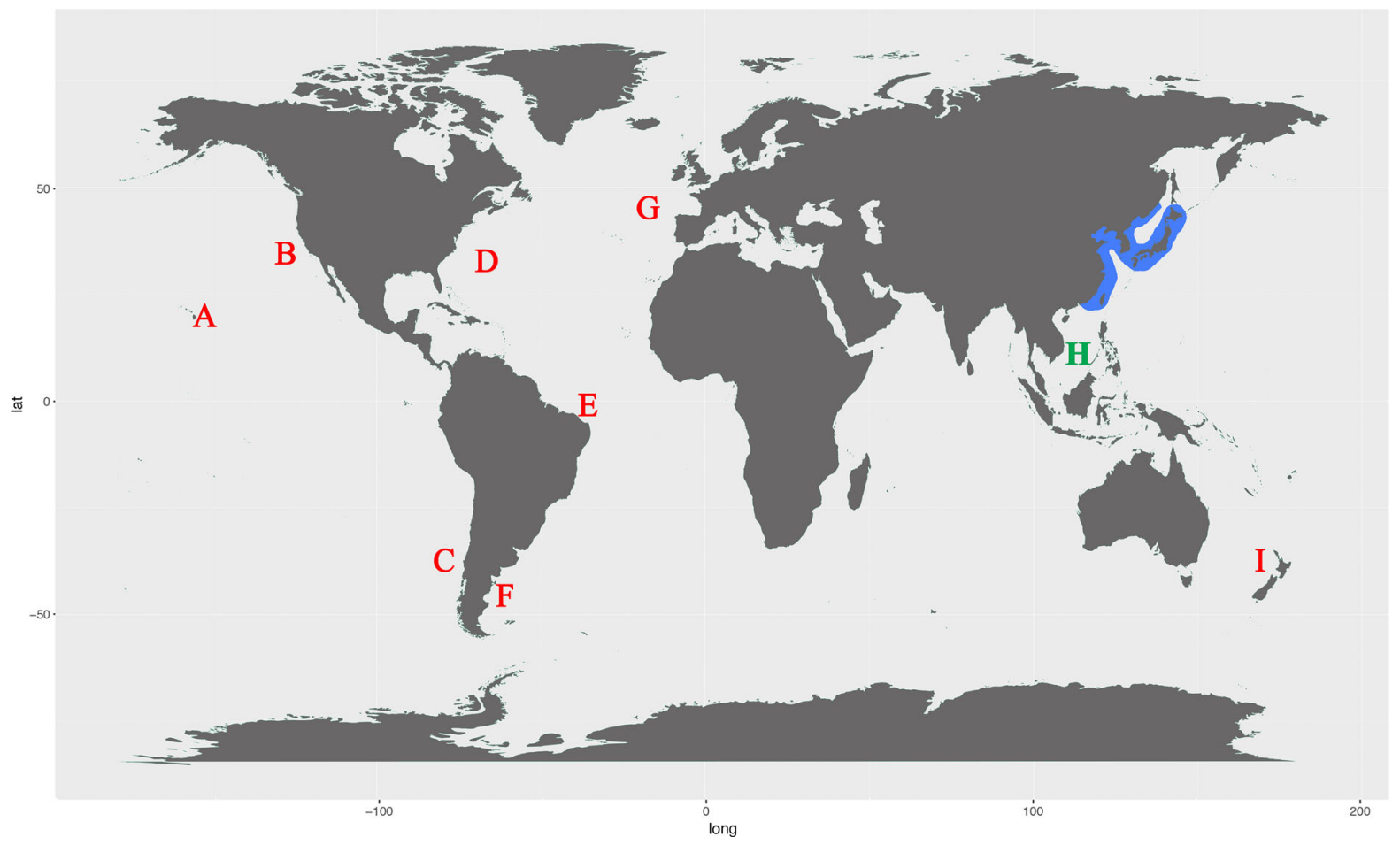

Fig. 4 Map of the native (blue shading), introduced (red letters), and cryptogenic (green letter) distribution of Diadumene lineata. References including dates of original regional detection and/or of additional distribution data: a Hawaii (Zabin et al. 2004; Carlton and Eldredge 2015); b Pacific coast of North America from Sitka, Alaska to San Diego Bay, California (Carlton 1979a, b; Fofonoff et al. 2019a, b, c; J. T. Carlton, personal observations, iNaturalist observations); c Chile (Häussermann et al. 2015); d Canadian Maritimes to the Gulf

conditions (Verrill 1898; Sassaman and Mangum 1970; Shick 1991), seasonal climates, and no doubt through transport episodes across wide latitudes. In northern latitudes, individuals of $D$. lineata may shrink to a dormant phase during the winter to the point of a population nearly disappearing or becoming regionally extinct, with some of these populations then flourishing again in the spring and summer when water warms (Allee 1919; Stephenson 1935; J. T. Carlton and M. Flenniken, personal observations). In southern latitudes, the reverse occurs where body size increases during the winter and spring and decreases throughout the summer (Ryan 2018). Studies on body sizes indicate that these regional differences are influenced largely by fission and growth reactions to temperature, as an individual will peak in body size at $14{ }^{\circ} \mathrm{C}$ (Ryan et al. 2019). of Mexico (Verrill 1898; Shick 1976; Hancock et al. 2017; Fofonoff et al. 2019a, b, c; Ryan and Miller 2019; Ryan et al. 2019; Ma et al. 2020; all authors, personal observations); e Brazil (Belém and Monteira 1977); f Argentina (Molina et al. 2009); g Western Europe south to the Canary Islands, through the Mediterranean to the Black Sea (Stephenson 1935; Podbielski et al. 2016; Fofonoff et al. 2019a, b, c; iNaturalist observations); h Malaysia and Indonesia (Dunn 1982); i Australia and New Zealand (Dunn 1982)

Reproduction in D. lineata can occur either sexually or asexually through rapid fissipary involving either pedal laceration or binary longitudinal fission, the latter being the most common method of asexual reproduction in sea anemones (Shick 1991; Bocharova and Kozevich 2011). Asexual proliferation of $D$. lineata can occur very rapidly and extensively (Stephenson 1935; Shick and Lamb 1977). In its native range in Japan, both males and females cooccur, with successful sexual reproduction occurring in the summer, based on the collection of planktonic larvae from externally fertilized gametes (Uchida 1932; Fukui 1991). However, larval settlement and recruitment have not yet been observed outside of laboratory settings (Fukui 1991). Outside of Japan, mixed-sex populations of $D$. lineata were previously seldom reported, having been recorded as typically only female (Hieb 1977; Dunn 1982), male (Shick 
1976; Shick and Lamb 1977) or sterile (Dunn 1982). Recent work, however, has revealed sympatric populations with eggs and sperm from Massachusetts to Florida (Ryan and Miller 2019), as well as in Coos Bay, Oregon (Newcomer et al. 2019). Nevertheless, larval production and release, and individuals recruiting as a result of larval settlement, remain unknown in the wild in this species.

The native range of $D$. lineata is from at least Hokkaido, Japan south to Hong Kong (type locality; Fig. 4; see Uchida 1932). It was originally assigned to Sagartia (Verrill 1869), and later studied in Japan as Diadumene luciae (Uchida 1932). The species was mistakenly redescribed in the Atlantic as a distinct species (Sagartia luciae) in 1898 by Verrill, later transferred to the genus Haliplanella Hand, 1956, and eventually synonymized with Verrill's own species (Sagartia lineata) described 29 years earlier from China (nomenclatural history reviewed by Hancock et al. 2017). There are now populations throughout the world (Fig. 4) except for Africa and Antarctica (Fofonoff et al. 2019a, b, c). Genetic studies will be required to determine whether populations found in Malaysia (Jebram, Selangor), Brazil/Argentina (southeast and northeast, Gusmão et al. 2018), or Indonesia (Dobo, Aru Islands; Dunn 1982; Fig. 4) are (1) native and represent the southern end points of the Asian range of D. lineata, (2) introduced, or (3) represent a cryptic tropical sibling species, given that most other global populations occur only in temperate waters. The reasonably well-known timing of appearances of $D$. lineata around the world appears to be episodic, which is a pattern similar to other introduced species in which spread occurs in multiple pulses of invasion (Carlton and Cohen 2003).

\section{Diadumene leucolena (Verrill, 1866)}

The ghost anemone Diadumene leucolena has a height of $3 \mathrm{~cm}$, with a generally thinner, taller, and paler appearance than D. lineata (Hand 1956), always lacking the striking orange or white lines of the latter (Ryan and Kubota 2016). The species inhabits shallow marine and brackish habitats, including artificial substrates such as docks and piers, preferring shaded areas (Field 1949; Hand 1956; Cory 1967; Sassaman and Mangum 1970).

Diadumene leucolena is sensitive to temperatures below $17.5{ }^{\circ} \mathrm{C}$ (Sassaman and Mangum 1970). Like its congener $D$. lineata, D. leucolena is euryhaline, being particularly tolerant of low salinities (Pierce and Minasian 1974). The few reports within the native range (e.g. Field 1949) that characterize it as possessing pedal laceration are questionable (see Hand 1956) and have been discounted in later literature to the point that it is believed to be only sexually reproducing (Shick and Lamb 1977; Hand 1956; Fofonoff et al. 2019b).

The native range (Fig. 5) of D. leucolena is from New Brunswick, Canada (Fofonoff et al. 2019b) to the Caribbean, the latter including Puerto Rico (material identified by J. C. den Hartog; see Fofonoff et al. 2019a, b, c; perhaps the same as "West Indies" reported by Cuttress, 1977) and Curacao (identified by J. C. den Hartog, fide Beneti et al. 2015). Diadumene leucolena has been introduced (Fig. 5) to the Eastern Atlantic Ocean and to the Indian and Pacific Oceans. In the Central Eastern Atlantic, populations have been reported from Morocco, the Canary Islands, and Senegal (Ocaña and den Hartog, 2002; Ocaña et al. 2015). Reports of it from Cameroon, Gulf of Guinea were based upon the presumed synonymy with Diadumene kameruniensis Carlgren, 1927 (Ocaña and den Hartog 2002), which is retained as a distinct species by Fautin (2016). In the Eastern North Pacific, populations have been reported from Coos Bay, Oregon to the northern Gulf of California (Hand 1956; Carlton 1979a, Wasson et al. 2001), with a perhaps disjunct population on the Pacific coast of Panama in Panama Bay (Reimer 1976, material identified by C. E. Cutress), although sites south of the Gulf of California have been insufficiently explored. It has been known since the 1950s from O'ahu, Hawaii (Carlton and Eldredge 2009). In the Indian Ocean, it is reported from South Andaman Island in the northwest Indian Ocean (Raghunathan and Choudhury 2017). As with D. lineata, its presence both in the tropics and in temperate (to $-1{ }^{\circ} \mathrm{C}$ in winter) locations may indicate the presence of cryptic speciation within D. leucolena as well.

\section{Diadumene franciscana (Hand, 1956)}

Diadumene franciscana is another small Diadumene species, with a height of 2-4 cm (Hand 1956). It was originally described from San Francisco Bay (Hand 1956), where it is a well-known component of shallow fouling communities on floats and pilings. Exposure to 


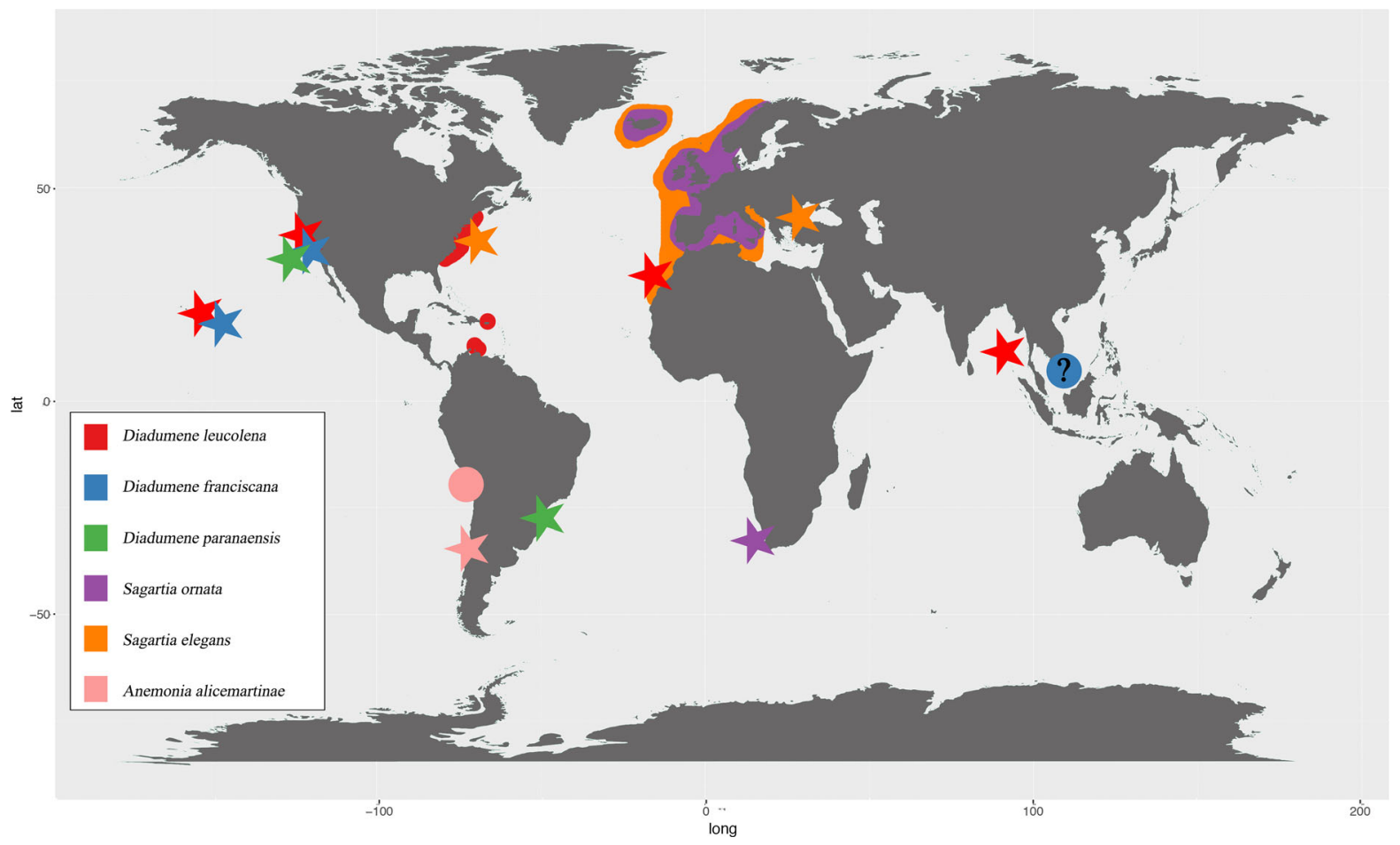

Fig. 5 Map of the native distribution of species of sea anemones (circles or shading) and the approximate locations of established introductions (starred), coded by color for each species according to the map legend. References for distributions are: Diadumene leucolena (Field 1949; Hand 1956; Sassaman and Mangum 1970; Carlton 1979a, b; Wasson et al. 2001; Carlton and Eldredge 2009); Diadumene franciscana, native range not yet known (Hand 1956; Carlton 1979b; Godwin et al. 2006); Diadumene paranaensis, native range not yet

low salinity does not have a negative effect on the species (Hand 1956), and, as it has been found in Hawaii, it can establish in warmer temperatures (Carlton and Eldredge 2009). Since the 1950s, it has been found from Tomales Bay to San Diego, California (reviewed in Fofonoff et al. 2019c).

Similar to other members of Diadumene, D. franciscana can reproduce both sexually and asexually by pedal laceration (Hand 1956). There is a possibility that $D$. franciscana is not native to the Eastern Pacific Ocean, but was instead introduced from the Western or Indo-West Pacific Oceans, as suggested by Hand (1956), Carlton (1979a, b) and Carlton and Eldredge (2009), based upon the improbability of it having been historically overlooked in the Eastern Pacific Ocean or being undetected in the Atlantic Ocean, and given the known (Gonzalez-Muñoz et al. 2012; Rodríguez et al. 2012; Beneti et al. 2015); Sagartia ornata (Stephenson 1935; Acuña et al. 2004; Mead et al. 2011); Sagartia elegans (confirmed but not established; Ates et al. 1998; Pederson et al. 2005; Wells 2013; Grebelnyi and Kovtun 2013; Wells and Harris 2019); Anemonia alicemartinae, native range unknown (Häussermann and Försterra 2001, 2005; Canales-Aguirre et al. 2015). In the present paper, the introduced locations of $S$. ornata is referred to as Sagartia sp. South Africa

extent of diadumenid diversity yet to be characterized in the Western Pacific and Indian Oceans (Fig. 5).

\section{Diadumene paranaensis (Beneti et al., 2015)}

Diadumene paranaensis is a small (6 $\mathrm{mm}$ height), orange-white anemone from shallow-water fouling communities in Brazil. Like its congeners D. lineata and D. leucolena, D. paranaensis reproduces asexually through longitudinal fission and lives attached to hard substrates such as bivalves, rocks, pilings, and dock floats (Beneti et al. 2015). Originally described from an estuary, D. paranaensis is resilient to variations in temperature, salinity and desiccation (Beneti et al. 2015).

The Brazilian population was assumed to be nonnative because it was found in a harbor and all 
individuals collected were interpreted to be clone mates as a result of asexual reproduction (Beneti et al. 2015). In addition, there appear to be no earlier, historical records of this species in Brazil. The description of $D$. paranaensis matches the anatomy and cnidom of a previously unidentified species of Diadumene (see Rodríguez et al. 2012, 2014: Fig. 2, Diadumene sp.) that had been collected from oil platforms in the Santa Barbara Channel CA (MD, personal observation) and from San Francisco Bay CA (Carlton 1979a; MD, personal observation). Although the individuals in each California population were not obviously clonemates, neither did they have characteristics of a native population, being found only in highly disturbed habitats and being absent from accounts of the anemone fauna before the 1970s (Carlton 1979a). Therefore, although two potential introduced regions have been identified, the native range is unknown (Fig. 5).

\section{Metridium senile (Linnaeus, 1761)}

Metridium senile, the fluffy or plumose sea anemone, is among the largest sea anemones, reaching to a meter in height (Stephenson 1935). The taxonomic history of the species has been challenging, as there has been long-term confusion between how to identify and apply the names of M. senile and Metridium dianthus (Ellis, 1768) of the northeastern Atlantic. For the purposes of this paper and since both descriptions of the species possess the same life history strategies, we treat records of Metridium senile and Metridium dianthus here under the name M. senile. Metridium senile occurs from the intertidal zone to depths exceeding $100 \mathrm{~m}$, although their occurrence is limited by the availability of hard substrate such as bivalves, rocks, docks, pilings, and shipwrecks (Carlgren 1933; Hoffmann 1976).

Metridium senile is robust in its responses to changes in water temperature, tolerating short exposures to temperatures up to $24{ }^{\circ} \mathrm{C}$, although it is primarily found in cooler waters (below freezing to $20{ }^{\circ} \mathrm{C}$ : Stephenson 1935; Glon et al. 2019). They are also tolerant of a broad range of salinities from 14.8 to $37.5 \%$, enabling them to thrive in both the open ocean and occasionally in estuarine conditions (Shumway 1978; Glon et al. 2019). At lower latitudes, populations become more patchy and move increasingly into cooler sublittoral depths (Walsh and Somero 1981; Shick 1991).

Metridium senile exhibits both sexual and asexual reproduction through pedal laceration. The species is an oviparous broadcast spawner, undergoing external fertilization upon release of gametes in late summer to early fall to produce free-swimming planula larvae (Bucklin 1982; Lombardi and Lesser 2010). Although an exact length of time that these larvae are able to exist planktonically is unknown, they are believed to stay in this stage for several months, being readily dispersed or carried over long distances to new habitat (Gemmill 1920; Hoffmann 1987). The more common method of reproduction is asexual reproduction by pedal laceration, which can occur in all individuals, at all times of year, and lead to dense clonal groups (Hand 1956; Hoffmann 1987; Lombardi and Lesser 2010; Glon et al. 2019).

Dispersal may occur via planktonic larvae (Hoffmann 1986; Anthony and Svane 1995), by rafting on marine debris (Goldstein et al. 2014, Carlton et al. 2017, see below) or on detached algae (J. T. Carlton, personal observations, Coos Bay, Oregon). Although sexual reproduction through spawning is considered to be the primary means of dispersal, passive drifting of adults following detachment in response to a disturbance may also occur. Drifting behavior can be triggered by biotic factors such as exposure to the predatory nudibranch Aeolidia papillosa (Linnaeus, 1761; Shick et al. 1979) or by abiotic factors such as anoxic conditions which enable drifting through the ballooning of the pedal disc (Shick et al. 1979; Wahl 1985).

Of the six putative species of Metridium de Blainville 1824, M. senile has the broadest range, with a circumboreal distribution that overlaps with nearly every other species in the genus (Stephenson 1935; Hand 1956; Fautin 2016). Metridium senile is considered to be introduced to several regions in the southern hemisphere, with robust established populations in South America, South Africa, and the Falkland Islands (Fig. 6). Additionally, although the range of M. senile is circumboreal in the Northern Hemisphere, its status as a native to the Pacific Ocean has been disputed. Despite the endemicity of other Metridium species in the Pacific, the presence of $M$. senile was not well documented until the mid- to late-1800s, at which time it was noted only in harbors and bays. Originally described by Verrill (1865) as Metridium fimbriatum 


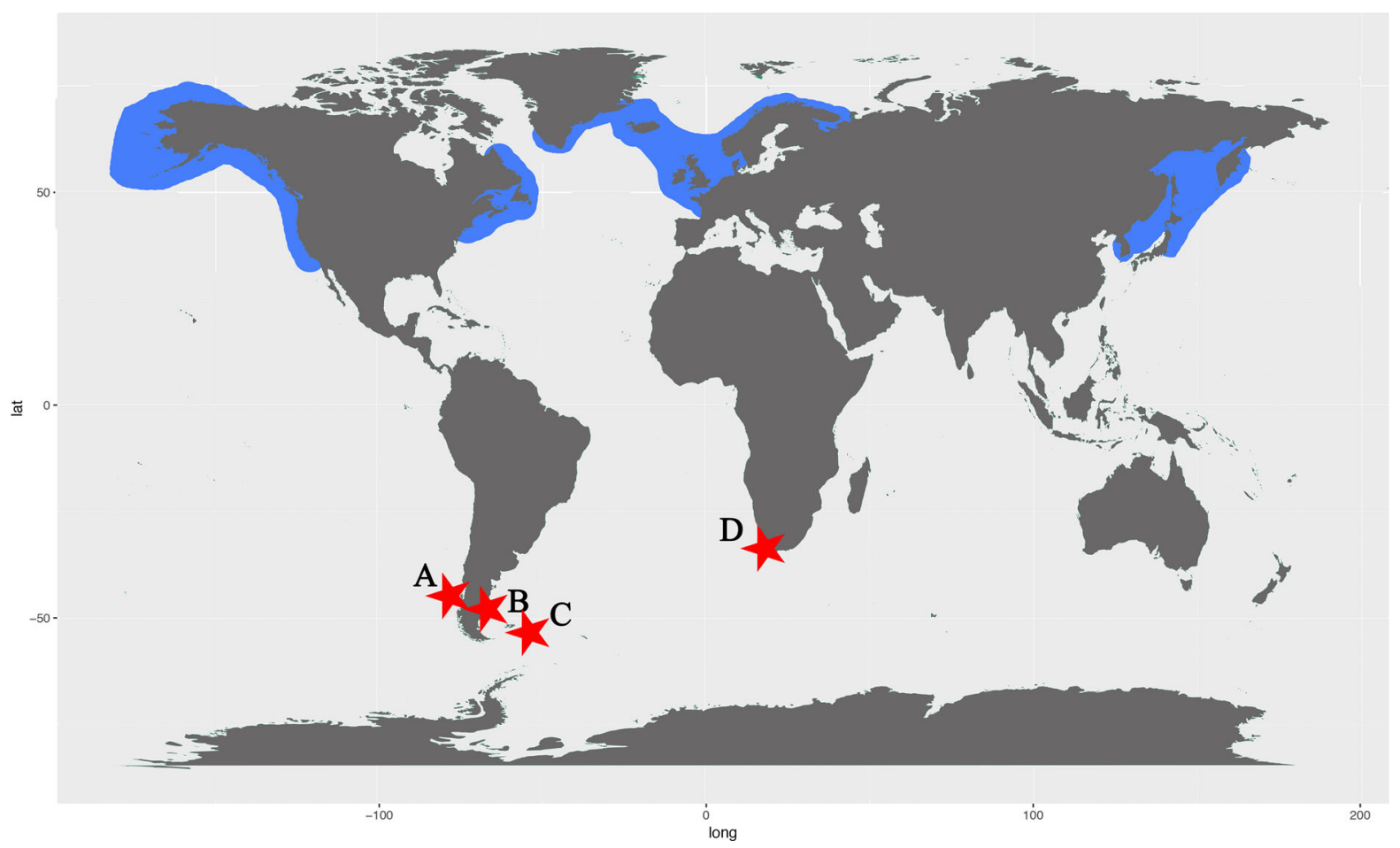

Fig. 6 Map of the native distribution of Metridium senile (blue shading). Approximate locations of established introductions are starred, with references including both those of dates of original regional detection and of important distribution information: a Chile (McMurrich 1904; Riemann-Zürneck

from San Francisco Bay, he soon recognized that it likely belonged to the same highly variable species (M. senile) present in the Atlantic Ocean (Verrill 1869). In the early 1900s, Kofoid (1915) suggested it was introduced to San Francisco Bay, with a later statement of it "contaminating" San Diego harbors and other ports through shipping traffic (Kofoid 1915). Carlton (2011) suggested that the reason for Kofoid's comment may have been because $M$. senile established in Eastern Pacific harbors within the span of human memory at that time. MacGinitie (1935) stated that, "It has been claimed that Metridium was introduced from the east coast with oyster spat. This is no doubt a mistake, for it is circumboreal in distribution." While it would not be impossible for Metridium from the United States Atlantic coast to have been transported to the Pacific coast in the late 1800s with commercial oysters, the source of MacGinitie's reference to such a claim remains unknown (Carlton 1979a).
1986; Häussermann and Försterra 2005); b Argentina (Riemann-Zürneck 1975; Martin et al. 2015); c Falkland Islands (Glon 2020); d Table Bay Harbor \& Agulhas Bank, South Africa (Griffiths et al. 1996; Laird and Griffiths 2016)

\section{Sagartia sp. "South Africa"}

Acuña et al. (2004) identified Sagartia populations first collected in 2001 in South Africa (Fig. 5) as the viviparous European species $S$. ornata, which reaches a height of $14.4 \mathrm{~mm}$ (Shaw et al. 1987; Ates et al. 1998). The African populations brood parthenogenic young, reaching densities that exceed 500 individuals/ $\mathrm{m}^{2}$ in intertidal communities in the region of West Cape (Robinson and Swart 2015). However, Hartog and Ates (2011) and R. Ates (personal communication, 2019), note that the description of the cnidom of South African populations does not match that known for $S$. ornata, and emphasize further that the possession of zooxanthellae in the South African Sagartia is anomalous for the genus (but that the closely related Cereus is known to be photosymbiotic).

Sagartia ornata in Europe occurs intertidally on hard substrate, with a range that extends farther than other Sagartia species into estuaries and other marginal habitats (Stephenson 1935). In contrast, 
Robinson and Swart (2015) emphasized that the Sagartia living in Langebaan Lagoon on the west coast of South Africa lived in distinctly different habitats-shallow sand, in salt marsh Spartina maritima meadows and in eelgrass Nanozostera capensis beds, as well as on loose rocks "on fossilized oyster beds." This habitat divergence may provide an additional clue that a species other than $S$. ornata may be involved, rather than being an example of a habitat shift in an invading species, as proposed by Robinson and Swart (2015).

The restricted occurrence of this presumably alien species has so far limited its impact in South Africa, but where it does occur it is associated with a change in the fauna. This includes an increase in the relative abundances of the tanaid crustacean Anatanais gracilis (Heller, 1865) and the polychaete worm Orbinia angrapequensis (Augener, 1918), in both cases correlated with the anemone's ability to consolidate sand and trap coarse sediment (Robinson and Swart 2015).

\section{Sagartia elegans}

A large population of a non-native Sagartia, identified as S. elegans (Dalyell, 1848), was discovered in a marina in the Gulf of Maine, in Salem, Massachusetts, in 2000 (Pederson et al. 2005; Wells and Harris 2019); previous to this discovery, no members of the genus Sagartia were known from the Northwest Atlantic Ocean. However, the population disappeared by 2010 , likely due to the warm water effluent flowing into the marina (which had kept the area warmer than ambient in the winter) ceasing when an adjacent power plant shut down (Wells and Harris, 2019; C. Wells, personal communication). In its native European range, $S$. elegans undergoes boom-and-bust cycles, disappearing following harsh winters or expanding at the range edges during mild winters, with a notable sensitivity to extreme cold (Ates et al. 1998).

Sagartia elegans is a well-known northern European species reaching a height of $4.5 \mathrm{~cm}$, inhabiting coastal and mildly brackish habitats from Scandinavia to North Africa (Fig. 5; Grebelnyi and Kovtun 2013). The species is typically found in the low intertidal to subtidal attached to or in hard substrates, but can also be found at deeper depths to $90 \mathrm{~m}$ (Stephenson 1935). Relatively recent reports of large populations in the Black Sea (Grebelnyi and Kovtun 2013) may reflect a range expansion into that more brackish and highly disturbed system. Sagartia elegans reproduces both sexually and through pedal laceration (see Ates et al. 1998; Shaw 1991; Grebelnyi and Kovtun 2013).

As we note later, of interest is that an anemone apparently similar to Sagartia elegans has been recorded (as Sagartia "rosea," a submerged invalid name for S. elegans; Fautin, 2016) as abundant in fouling communities on offshore structures in China (Yan \& Yan 2003). We consider the identity of the $S$. elegans population formerly reported from Massachusetts to be uncertain in the absence of genetic confirmation, and thus it may not be identical with the S. elegans known in Europe.

Exaiptasia pallida (Agassiz in Verrill, 1864)

Exaiptasia pallida is often reported under its former name Aiptasia pallida or under the name Exaiptasia diaphana (Rapp, 1829; see Grajales and Rodríguez 2014, 2019). It has long been reported (under many other names as well, below) from throughout the North and South Atlantic Oceans, including western Europe, the Mediterranean, the west coast of Africa (and St. Helena Island), the west coast of South America, throughout the Caribbean and the Gulf of Mexico (including the Atlantic coasts of Mexico and Panama), and the southwest coast of the United States (Grajales and Rodríguez 2014, 2016). This broad distribution suggests that its highly disjunct distribution in the Pacific Ocean may represent introduced populations. In the Eastern Pacific it is known from southern California to Mexico, Panama, and the Galapagos, in the Central Pacific from the Hawaiian Islands, and in Western Pacific from Australia and Japan, as well as the Red Sea in the Indian Ocean (Mito and Uesugi 2004; Thornhill et al. 2013; Grajales and Rodríguez 2014; Carlton et al. 2019). The broad range obscures its origin, but we suggest below that E. pallida may be native to the Western Atlantic.

E. pallida is a noted pest in the aquarium trade (Ram 2013). In the wild, E. pallida lives in reef habitats, on mangroves, and on pilings, floats, and other man-made structures, generally growing to an expanded size of $60 \mathrm{~cm}$ in height. Because they are prolific asexual reproducers, E. pallida tends to form extensive monocultures on suitable hard substrates. The speed with which it covers substrate is a point of concern for aquarists, who note that it grows over corals and other ornamentals and can clog aquarium 
filters (Ram 2013). Exaiptasia pallida may play a similar fouling role in native environments, as it is often found on shells, coral skeletons, and the roots of mangroves, and this proliferative power makes its appearance of concern in sensitive environments such as isolated marine lakes (Hanzawa et al. 2012; Patris et al. 2019), in Madeira (Canning-Clode et al. 2013; Wirtz 2014) and in the Galapagos Islands (Carlton et al. 2019), although the quantified effects of $E$. pallida in these systems so far has either not been studied or is minimal (Patris et al. 2019). Experimental competitive interactions between E. pallida and native European species indicate that it is competitively matched by ecologically similar native species and thus unlikely to become dominant (Escribano-Álvarez and López-González 2018). However, its broad ecological tolerance, ability to thrive in acidic waters (Hoadley et al. 2015), and its introduction into regions with novel suites of anemone species may provide advantage to E. pallida in new regions.

Although it is most commonly found in tropical environments that experience a relatively narrow range of temperatures and salinities, E. pallida shows broad physiological tolerance. Unlike many photosymbiotic cnidarians, E. pallida maintains its symbiosis under thermal and salinity stress, and shows enhanced thermal tolerance when under salinity stress (Gegner et al. 2017). Although E. pallida associates with symbiotic dinoflagellates (Symbiodinaceae), this symbiosis is more flexible than in many other cnidarians: E. pallida can harbor symbionts from the genera Symbiodinium, Breviolum, and Cladocopium (see Thornhill et al. 2013; LaJeunesse et al. 2018), and can also survive without them. Exaiptasia pallida exhibits remarkable plasticity in reproduction. It is capable of asexual reproduction via longitudinal fission to generate two similarly-sized, feeding daughters, via pedal laceration to produce smaller daughters, and can also produce tentacle-less polyps under stress, described as a "wurst" form (Hunter 1984; Shick 1991; Rädecker et al. 2019). Although generally gonochoric, clonally produced offspring can mature into adults that differ in sex from their parent and some individuals switch from gonochoric to hermaphroditic, with self-fertilization possible in hermaphrodites (Schlesinger et al. 2010). This biological plasticity is one reason that E. pallida has become an important emerging model for anthozoan biology and genetics (reviewed by Rädecker et al. 2018).
As in M. senile, the taxonomic history of E. pallida is complex. The taxon as currently recognized includes concepts associated with nine nominal species (see Grajales and Rodríguez 2014). Both Aiptasia pallida and A. pulchella had been recognized as introduced species in the Pacific, but with more limited ranges (Okey et al. 2003; Mito and Uesugi 2004; reviewed by Grajales and Rodríguez 2014); the synonymy of these with several more species with narrow ranges partly explains the global distribution of E. pallida. The type locality of E. pallida is the North American Atlantic coast. The type locality of $A$. diaphana (Rapp, 1829) is Naples, Italy, while further synonyms include A. inula (Duchassaing and Michelotti, 1864), A. mimosa Duchassaing and Michelotti, 1864), and A. tagetes (Duchassaing and Michelotti, 1864), all described from the Caribbean. Aiptasia minuta (Verrill, 1867) was described from Japan, but its identity is controversial, as there are no type specimens and some authors have considered it to belong to Aiptasiomorpha, rather than Aiptasia (see Uchida and Soyama 2001; Grajales and Rodríguez 2014). Records from the mid-Atlantic came later (Fig. 7), with the earliest record being that of $A$. insignis (Carlgren 1941) from St. Helena. Records from the tropical Pacific (as Aiptasia pulchella Carlgren 1943) and from the eastern Pacific (as Aiptasia californica Carlgren, 1952) were described within the next decade.

The complexity of this taxonomic history complicates the effort to reconstruct a clear invasion history at this time of E. pallida. For example, it is considered as a "non-indigenous" species in France (Ardura and Planes 2017), as it is assumed to have been introduced by mariculture of the imported Japanese oyster Crassostrea gigas (Grizel and Heral 1991). However, it was first identified as the Pacific Aiptasia pulchella, a name now placed in the synonymy of E. pallida, which was present in Europe before Japanese oyster culture began in France in the 1970s.

Molecular analyses of E. pallida have identified three narrowly-restricted genetic populations and one widespread genetic population. The narrowly-restricted populations are from Florida (Thornhill et al. 2013, Bellis et al. 2016), Brazil (Grajales and Rodríguez 2016), and Atlantic Panama (Bellis et al. 2018); the Brazilian species has been described (as Exaiptasia brasiliensis Grajales and Rodríguez 2016) but the Floridian and Panamanian populations have 


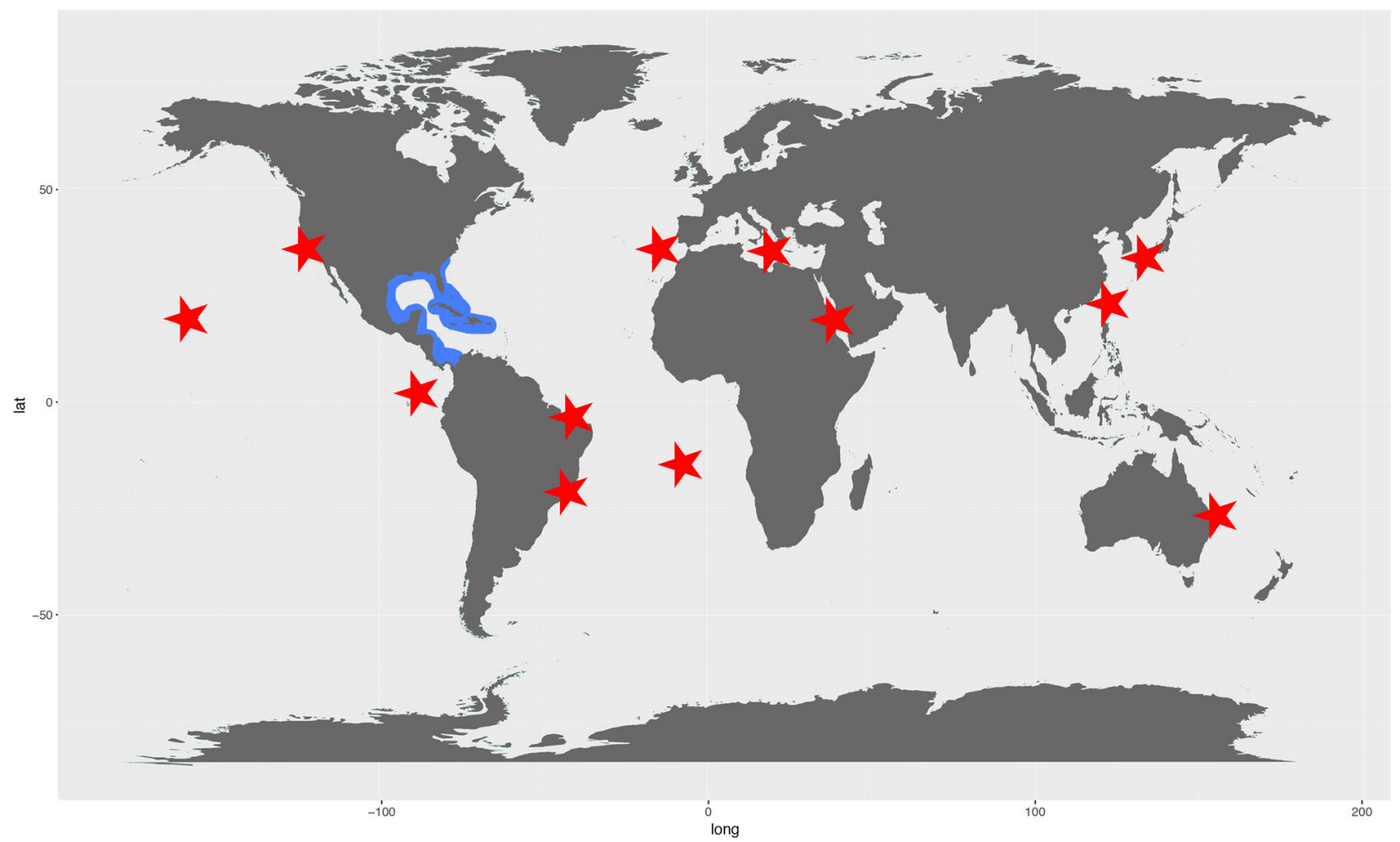

Fig. 7 Map of the presumed native distribution of Exaiptasia pallida (blue shading). Approximate general locations of established introductions are starred, with references including

not been taxonomically differentiated from E. pallida. The widespread populations encompasses all other locations, spanning oceans and continents and cooccurring with the more narrowly distributed populations (Thornhill et al. 2013; Grajales and Rodríguez 2016; Bellis et al. 2018). The genetic markers that have been used to elucidate relationships within this widespread clade are insufficiently variable to discern points of origin, but the existence of apparently endemic clades in the broader Tropical West Atlantic might be a clue as to its origin: E. pallida may have split from E. brasiliensis and from the unnamed Floridian and Panamanian populations before it was introduced elsewhere, which suggest that it originated in the Caribbean or Tropical West Atlantic.

\section{Anemonia alicemartinae (Häussermann} and Försterra, 2001)

Anemonia alicemartinae is a bright red anemone with a height of generally less than $25 \mathrm{~mm}$. It appears to be a habitat generalist, being found commonly on rocks from the intertidal to $16 \mathrm{~m}$ over a range of $13-23{ }^{\circ} \mathrm{C}$ in those of dates of original regional detection and/or of important distribution information included in the text and as noted in Grajales and Rodríguez (2014)

normal open ocean salinities (33-36\%), as well as living on macroalgae, stones, marine debris, and crabs (Häussermann and Försterra 2001). It also occurs in fouling communities in Chile (J. T. Carlton, personal observations). Reproduction occurs through frequent longitudinal fission, and although fertile specimens have been recorded, these have all been female, which suggests clonal populations (Häussermann and Försterra 2001). In light of the single sex populations and its ability for quick attachment and reattachment of the pedal disc, A. alicemartinae is inferred to spread only as adult anemones.

The species was first described from Chile, but is presumed to have been introduced to Chile from elsewhere because it was not recorded in surveys until 1975 (Fig. 5; see Häussermann and Försterra 2001). Population genetics support the hypothesis that the single-sex Chilean populations of A. alicemartinae originated from a small population to the north, in the south of Peru, from which individuals may have then been transported southward in ship hull biofouling (Canales-Aguirre et al. 2015). 
The absence of this colorful, conspicuous, relatively large, easily accessible and abundant intertidal sea anemone from the historical literature of South American west coast anemones, including in Peru (Häussermann and Försterra 2001), as well as the absence of any other species of Anemonia in the Eastern Pacific Ocean (and thus the improbability of a short-range ancient endemic existing only in southern Peru) strongly suggest that $A$. alicemartinae has been introduced from either the Indo-West Pacific or from the Atlantic Ocean. A phylogeny of known Anemonia species may thus place A. alicemartinae with Eastern Atlantic-Mediterranean, Western Atlantic, or IndoWest Pacific clades.

\section{Nematostella vectensis (Stephenson, 1935)}

The starlet sea anemone Nematostella vectensis is a small species (4-6 mm height) which burrows into the fine, often anoxic sediments within marsh pools or creek banks, and frequently occurring in intertidal mats of the yellow-green alga Vaucheria (Stephenson 1935; Hand and Uhlinger 1992, 1994). Populations generally are found in brackish habitats within coastal saltmarshes, and are resilient to extremes of salinity (9-51.5\%o) and temperature $\left(-1^{\circ}\right.$ to $28{ }^{\circ} \mathrm{C}$ ) (Hand and Uhlinger 1992). The broad thermal (Bleakney and Meyer 1979; Kneib 1988; Reitzel et al. 2013a, b) and salinity (Hand and Uhlinger 1992) tolerances of $N$. vectensis likely aid in its invasion success.

Although much is known about the genetics and physiology of $N$. vectensis because of its adoption as a model biological system (Hand and Uhlinger 1994; Darling et al. 2005; Layden et al. 2016) relatively little is known about its ecology or about the impact it might have in the regions into which it has been introduced. In its native range, $N$. vectensis is prey for small crustaceans and probably for bottom-feeding fish (Kneib 1988, 1991; Posey and Hines 1991); in turn, it eats small arthropods, worms, and molluscs (Lindsay 1975; Frank and Bleakney 1976; Williams 1983; Posey and Hines 1991; Sheader et al. 1997). As these general classes of prey are broadly available, the diet of $N$. vectensis is likely conserved across its range, although the specific identity and relative composition of the diet predictably fluctuates at spatial and temporal scales. While we have found no studies of the ecology of Nematostella in its introduced range (below), Posey and Hines (1991), in experimental studies conducted in Chesapeake Bay, found that $N$. vectensis significantly reduced the abundance of certain benthic prey species.

The species can undergo both sexual and asexual reproduction by transverse fission (Shick 1991; Hand and Uhlinger 1994). In their native range, $N$. vectensis is a dioecious seasonal reproducer in late summer (Frank and Bleakney 1976; Hand and Uhlinger 1992), although they can be induced to spawn more frequently in captivity (Hand and Uhlinger 1992). Because they are small, live in sediments, and are translucent, they are not easily detected and are likely more widespread than reported (Hand and Uhlinger 1994). Although some populations are quite large (Hand 1957; Williams 1975; Hand and Uhlinger 1992), others are small or ephemeral (Bleakney and Meyer 1979; Williams 1983, 1987; Sheader et al. 1997).

First described from the Isle of Wight (Stephenson, 1935), the species was subsequently identified in salt marshes on the east and west coasts of North America and elsewhere in England (Fig. 8; reviewed by Hand and Uhlinger 1994; Reitzel et al. 2008). The relatively small size of the population in England led to the listing of the species as vulnerable to extinction due to habitat loss (Williams 1983) and the subsequent development of a conservation plan (reviewed in Sheader et al., 1997). Because of its broad and disjunct range, $N$. vectensis was initially assumed to represent multiple species (Crowell 1946). After the uniformity of individuals across the range was determined (Hand 1957; Williams 1975), a human-mediated, rather than natural, mechanism for dispersal became plausible (Hand and Uhlinger 1994). Early genetic assays of the populations in the UK showed that those populations consisted of single clonal genotypes (Pearson et al. 2002), and studies of the populations in the Eastern United States failed to find any correspondence between geographic and genetic distance (Darling et al. 2004). Fine-scale, range wide studies (Reitzel et al. 2008, 2013a, b; Darling et al. 2009) revealed that populations from the UK and from Pacific coast of North America had the closest affinity to populations from the American Atlantic coast, suggesting introduction from the American Atlantic to both the Pacific Ocean and to Europe. The split between the UK and North American populations is a relatively deep one (Reitzel et al. 2008). At the time of the study, all studied populations in the UK represented a single 


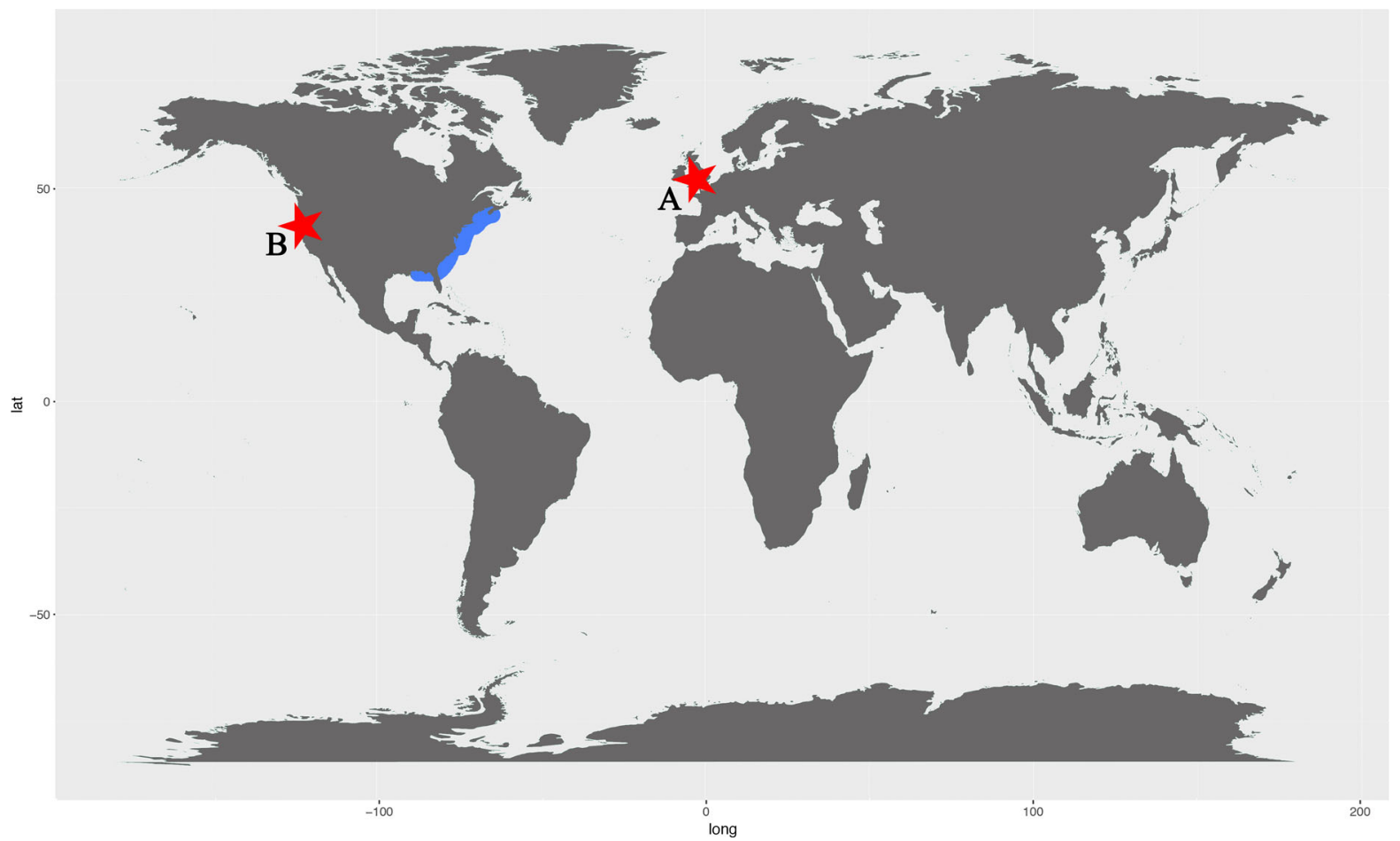

Fig. 8 Map of the native distribution of Nematostella vectensis (blue shading), based on Hand and Uhlinger 1994. Approximate locations of established introductions are starred, with references including those of dates of original regional detection and/

genetic cluster, as did each population in Western North America (Reitzel et al. 2008), suggesting a single founding invasion for each. As patterns of genetic similarity and diversity in North Eastern North America suggest that this is the native range of $N$. vectensis (see Reitzel et al. 2008, 2013a, b), its protected status in the $\mathrm{UK}$ is ironic.

\section{Factors and strategies leading to successful introduction}

The probabilities of completing each of the four main stages of introduction (Fig. 1) are heavily influenced by the life history strategies of each of the species considered here. Nearly all of the species examined in this review have completed all the stages to become introduced species, with the exception of Sagartia elegans, but other anemone species have traits which readily lend themselves to potential invasion success. or of important distribution information. a Three locations in the U.K. (Stephenson, 1935; reviewed by Hand and Uhlinger 1994; Reitzel et al. 2008); b Pacific Coast of Oregon, Washington and California south to San Francisco

\section{Transport stage}

Active dispersal by sea anemones is limited to crawling or floating of adults, dispersal of gametes into the water column, and swimming larvae. Although long-lived gametes and larvae are possible, and may explain some broadly distributed species, long-distance transoceanic and interoceanic dispersal is typically mediated by rafting or by human mechanisms.

Anthropogenic debris resulting from the 2011 Japanese tsunami has traveled eastward over a span of more than eight years through the North Pacific carrying living Asian animal and plant communities that have landed in North America and the Hawaiian Islands (Carlton et al. 2017; JTC, personal observations). Several of these arriving communities contained M. senile, D. lineata, Anthopleura sp., and several unidentified anemone species (Carlton et al. 2017; JTC personal observations). Such rafts are much slower (travelling at 1-2 knots) compared to commercial vessels (20-25 + knots; Kaluza et al. 2010), and 
thus the effects on sessile biofouling species differ significantly from ship-mediated transport: potential acclimatization time to changing environments would be beneficially longer, reduced water flow pressure may lead to less dislodgment, and the much greater transoceanic travel times (months and years for rafts versus days or weeks for vessels) means that much longer times are available for recruitment through asexual reproduction (Coutts et al. 2010). In addition, rafted objects that successfully land after an ocean crossing become potentially permanent landed "craft," as opposed to vessels that may spend only hours at a destination. In comparison with natural materials, anthropogenic (plastic) materials do not degrade as easily, creating a more stable, long-lasting substrate for transport (Carlton et al. 2017). Goldstein et al. (2014) reported finding anemones identified as Metridium sp., Calliactis sp., Anthopleura sp., Actiniidae, and Hormathiidae from rafting debris in the North Pacific Ocean.

Sea anemones may be transported as part of mariculture operations. Early awareness of this vector as an interprovincial phenomenon is found in the suggestion by Verrill (1898) that the intentional transport of oysters (Crassostrea virginica) from "the south" (meaning primarily at that time Chesapeake Bay) to Long Island Sound for commercial purposes may have transported Diadumene lineata to New England (even though the anemone was not yet known from southern waters). While numerous workers have invoked the commercial oyster industry as a likely vector for sea anemone introductions, actual records of sea anemones on transported and relaid oysters appear to be rare. Carl and Guiguet (1958) found $D$. lineata on newly imported Japanese oysters (Crassostrea gigas) arriving in British Columbia. Grizel and Heral (1991) found the anemone Aiptasia pulchella (now recognized as Exaiptasia pallida) on oysters (Crassostrea gigas) imported from Japan to France, and reported that it had survived and become established on the French Atlantic coast. The transplantation of shellfish and marsh grasses also may have mediated the introduction of $N$. vectensis to England and the Pacific coast of North America (Reitzel et al. 2008). In addition to their direct association with bivalves and marsh plants, anemones may be vectored by equipment such as fishing nets (Zabin et al. 2004) and boat fenders, hulls, rope, and gear (personal observations). The association of $E$. pallida with the ornamental aquarium industry, a vector typically linked to other non-native species invasions (Antoniadou and Chintiroglou 2007), suggest additional pathways for introductions.

Commercial shipping and cruise liners are instrumental in the movement of species in three significant ways: hull fouling, transport in ballast water, and attachment in sea-chests. Biofouling organisms on the hull of ships must be able to withstand sharp fluctuations in temperatures and salinity, as well as current depending on the speed of the ship (Coutts et al. 2010). Records of sea anemones surviving long-distance travel on ships' hulls have likely been under-reported, although reports of anemones on local and moored vessels are not uncommon (for example, Orton 1930, Sagartiogeton viduatus (Muller, 1776) (as Sagartia viduata) in England; Marine Biological Association 1957, Diadumene lineata (as Aiptasiomorpha lineata), in England; Farrapeira et al. 2007, Aiptasia pallida and Diadumene lineata, in Brazil; J. T. Carlton and M. Flenniken, Diadumene lineata in Connecticut; Spano et al. 2018, Anthothoe sp. in Australia). Visscher (1928) recorded Metridium sp. and Diadumene lineata (as Sagartia luciae) from unspecified ships' hulls. The first live observation of $D$. lineata as a passenger on the hull of an interoceanic ship was by Gollasch and Riemann-Zurneck (1996), who found it on a carcarrier vessel that had traversed around the globe from the Mediterranean to the Pacific Ocean and back to Europe; multiple D. lineata had attached to the live Japanese oyster, Crassostrea gigas, also on the hull. If a species is unable to persist in a high-flow area, a seachest (cavity-like structure on the hull of a ship providing a water intake for the ship) is a protected low-flow environment for producing extensive fouling communities (Frey et al. 2014). These have been found to successfully carry sea anemones across bodies of water (Coutts \& Dodgshun 2007).

Ballast water from ships acts as an ecologically non-selective vector, particularly for organisms with a pelagic life history stage. In San Francisco Bay, for example, many contemporary invasions are believed to result from ballast water (Carlton and Geller 1993). Carlton \& Geller (1993) were able to rear Metridium senile from larvae in ballast water from a Japanese ship that arrived in Coos Bay, Oregon (JTC, unpublished observations). Although $N$. vectensis also produces planula larvae, these live only a week before settling (Hand and Uhlinger 1992), and the species 
inhabits brackish, shallow pool habitats that are not likely sources of ballast water. However, since ballast water, when taken up, contains sediments which are not necessarily expelled when the ballast is released in the arrival port (Maglić et al. 2017), sediments can build up over time within the ballast tank or ballasted hold that can potentially provide suitable soft substrate suitable for some anemone species (Bailey et al. 2005; Briski et al. 2010, 2012). Modern ballast water management, which by the 2020s requires all ships at sea to have ballast treatment systems installed, may result in fewer ballast-mediated invasions (Batista et al. 2017; Campara et al. 2019; Davidson et al. 2017). This may perhaps mean that the longest-term shiprelated vector, hull biofouling, may return proportionally as the major vessel-related vector for global species transport.

In turn, one of the most common artificial substrates that introduced sea anemones inhabit are docks and piers in harbors. These serve as an immediate, available suitable substrate for species arriving on or in ships and can also serve as a source pool for the local area through both natural vectors and secondary anthropogenic-mediated dispersal. Both M. senile and Sagartia sp. South Africa have been introduced to South Africa (Figs. 5 and 6). In a harbor such as Table Bay where $M$. senile has established, shipping traffic is high and is assumed to have contributed either through fouling or ballast water to the introduction of many other introduced and cryptogenic species (Mead et al. 2011). The presence of M. senile in Argentina, particularly in fouling communities, corresponds with an increase in commercial shipping traffic since the 1980s (Martin et al. 2015), including possible transport from Chile around the tip of South America, where it has been well established since at least 2005 (Häussermann and Försterra 2005). Though A. alicemartinae has been highly influenced by changes in sea surface temperature and salinity, the expansion of the southernmost point of distribution is more likely due to the high maritime traffic present in the area (Pinochet et al. 2019). Cruise ships are also a large potential source of species movement: over 1.1 million tourists visited Alaska in 2018 via cruise ships, having increased from less than a million visitors 15 years prior (Ringer 2006; McDowell Group 2019). Alaska appears to be primed for transport and introduction of sea anemone species such as $M$. senile and D. lineata, as heavily frequented source ports are rich with potential invaders, the more so with climate change leading to warming polar and subpolar waters. Thus, the August 2019 discovery of D. lineata in Sitka, Alaska (https://www.inaturalist.org/observations/ 30146032) may reflect such newer invasion pattern scenarios.

The introduction of new species may correspond to events that result in increased ship-based travel. The California Gold Rush of 1848-1850, which brought many ships from around the world to the Pacific Coast, was responsible for new invasions in San Francisco Bay (Carlton 1996). Japan re-entered into global trade in the $1860 \mathrm{~s}$, and increased shipping exports a century later in the 1970s; these events align with the timing of the appearance of D. lineata in the northern (1890s) and southern (1970s) hemispheres (Table 1). Additionally, the added transport activity and new vessel routes during wartime have resulted in numerous introductions coinciding with world wars (see Carlton 1996 for review). The abundance of $M$. senile in California appeared to increase based on comments in the literature after the Gold Rush, World War II and the Korean War (Light 1941; Hand 1956; Purcell 1977; Purcell and Kitting 1982). Carlton (1979a) made the first speculation that $M$. senile from the Atlantic may have been introduced during the Gold Rush period in San Francisco in ship fouling biota; whether this was a new species introduction or a mixing of native Pacific populations with Atlantic populations remains unknown. Relative to E. pallida, the oldest records are in the 1800s from Europe, the Caribbean, and the Southeastern United States; as argued above, the probable native range for the species is the Tropical West Atlantic. These facts suggest that interoceanic and transcontinental trade, which was increasing at that time through the Caribbean, was the route by which E. pallida spread from the Tropical West Atlantic to Europe and the Pacific Ocean.

The three species $M$. senile, D. lineata, and $E$. pallida have been observed to detach and float in response to unsuitable conditions, and then to reattach and proliferate when conditions are more favorable (Davenport 1903; Wahl 1985; Bedgood et al. 2020. Similarly, A. alicemartinae has been observed to passively roll along the substrate or drift in the current (Häussermann and Försterra 2001). Since adults are potentially more tolerant to extremes than juveniles or gametes, the strategy of movement when adults may be beneficial to the species. The ease of detachment 
and reattachment to a substrate would increase the potential for colonizing a ship's hull, or conversely, detach from a ship's hull and colonize a new surface. Although toxic antifouling paints are commonly used on ships, some organisms (bryozoans and algae) are known to have tolerance to such paints, and can in turn provide a non-toxic substrate for the attachment of other species (Floerl et al. 2004; Briski et al. 2018).

Not surprisingly, most successful introductions of sea anemones have occurred in cases where the salinity and temperature are similar between the novel and native habitat, particularly when the putative native ranges cover large and ecologically diverse regions which likely allows for a high level of preexisting diversity and phenotypes readily able to acclimate. However, many of the successfully introduced species possess broad tolerances for salinity and temperature, and many are intertidal and thus tolerant of exposure to air. These traits may enable such species to survive the physiological challenges of long-distance transport. Species known to have broad tolerances to both temperature and salinity include $M$. senile, D. lineata, E. pallida, and N. vectensis. Those also tolerant to estuarine (brackish) water include $D$. paranaensis, D. leucolena, D. franciscana, and $S a$ gartia species. The only species not currently known to have a broad tolerance to temperature or salinity extremes is A. alicemartinae. Additionally, M. senile has been observed surviving in anoxic conditions for 5 days to 3 weeks, and up to 6 weeks for some individuals (Sassaman and Mangum 1972; Wahl 1984). Diadumene lineata has long been known to exhibit high physiological versatility, adaptable to both euryhaline and eurythermal conditions (Verrill 1898; Parker 1902; Uchida 1932; Miyawaki 1951; Sassaman and Mangum 1970; Shick 1976, 1991; Dunn 1982). The attributes of physiological flexibility may explain the phylogenetic clustering of introductionprone species, with more than half of the known invaders belonging to Diadumenidae or its sister family Metridiidae.

Rafting on natural substrates is possible, and anemones have been recorded from drifting algae, sea grass blades and rhizomes, and on shells (Cohen et al. 2005; Robertson 1962) as well as on pumice (Bryan et al. 2012). However, as introductions have consistently increased alongside historic rises in anthropogenic activity, human-mediated vectors are likely the mechanisms by which movement has been enabled across physical barriers or vast distances (Carlton 2003). As an individual is moved via one of these vectors, the tolerance to sharp fluctuations in temperature and salinity, depending on stage (larvae or polyp), is what determines the success of moving through the filter of transport to the introduction stage.

\section{Introduction stage}

Factors contributing to successful post-transport survival and introduction include basic physiological accommodation (reviewed above), traits of local dispersal capacity, individual behavior, and individual mobility, and the outcome of ecological interactions with the resident community (Cardeccia et al. 2018). Adaptations to the potentially temporarily harsh conditions that characterize long-distance transport may further facilitate the survival of a species upon arrival in a new location. Short-term behavioral responses (below) are likely more important in the Introduction phase than in the Transport phase, but faster, modern means of long distance transport may make Transport more similar to, and an extension of, the Introduction phase, rather than acting as a distinct, separate stage.

Behavioral responses of sea anemones to ecological stress include retracting tentacles, constricting the body column to reduce the surface area, and secreting copious amounts of mucus (Sassaman and Mangum 1970; Kiener 1972; Podbielski et al. 2016). In unfavorable environmental conditions, including decreasing salinity or exposure to air, sea anemones contract and produce mucus that "insulates" their bodies from those conditions (Sassaman and Mangum 1970; Shumway 1978; Häussermann and Försterra 2001). In D. lineata, this mucus hardens into a remarkable protective capsule, enabling it to withstand environmental extremes for unknown lengths of time (Kiener 1972; Carlton 1979a; Gollasch and RiemannZurneck 1996). The ability to enter into an encapsulated resting stage (encystment) allows $D$. lineata especially able to withstand physiological extremes, including desiccation and freshwater exposure (Uchida 1932; Kiener 1972; Carlton 1979a; Gollasch and Riemann-Zurneck 1996; Podbielski et al. 2016). Moving a ship into freshwater has been used to reduce biofouling (and inter alia, the potential transport of non-native species) but would likely be ineffective for $D$. lineata. The behavioral response of $M$. senile to 
freshwater is to detach and float away (Brock et al. 1999), which may also short circuit the efficacy of freshwater treatment and potentially facilitate introductions by the release of anemones into a region where tidal currents could transport them back into salt water.

Sea anemones have relatively low metabolic demands and generally diverse diets (Shick 1991), which facilitates both the Transport and Introduction phases of invasion. Encystment in D. lineata is accompanied by a metabolic slowdown, and M. senile can partially regulate metabolic rate in response to lowering temperatures, salinity changes, and oxygen availability (Sassaman and Mangum 1970, 1973; Shumway 1978).

\section{Establishment stage}

Anthropogenic activities and structures can create suitable environmental conditions that facilitate the introduction and establishment of non-native species. Artificial habitat within a suitable temperature regime or salinity zone may provide suitable substrate that otherwise may not naturally be present, and thus enable either direct colonization or serve to extend the range of a species and connect isolated metapopulations.

The broad range of habitat needs of many generalist sea anemones enables them to establish upon introduction. In addition to a wide range of anthropogenic surfaces, the habitat generalist $D$. lineata has been found on a wide range of natural substrates, including barnacles (Amphibalanus spp.), sea squirts (Molgula manhattensis), slipper limpets (Crepidula fornicata), spider crabs (Libinia emarginata), and wood ( $\mathrm{Z}$. Currimjee and M. Flenniken 2013, personal observation). Similarly, low substrate selectivity by the anemone Anemonia alicemartinae has been identified as one of the important traits leading to its invasion success (Thiel and Gutow 2005; Lopez et al. 2013).

Multiple cycles of introduction, survival and reproduction may be critical to the eventual establishment of a viable population, as well as the number of initially introduced individuals (Casties and Briski 2019). Numerous biotic pressures, including competition, predation, and disease (Alonso and Castro-Díez 2012) in a new region may influence the success of a species in establishment. Genetic characterization of D. lineata has revealed a potentially high diversity of unique clones among introduced populations, which indicates that multiple introductions may play an important role in the invasion success and spread of this species (Ting and Geller 2000). The introduction and retention of multiple genotypes would increase the long-term stability of a population, as genotype frequency might fluctuate over time. Competitive success, especially in highly disturbed environments, is a hallmark of successful invaders (e.g. Bando 2006) and is an attribute of at least some introduced anemones (Escribano-Álvarez and López-González 2018).

\section{Spread stage}

Physio-chemical tolerances, multiple modes of reproduction, broad habitat preference, and behavioral plasticity equip a species to succeed through the multiple steps in the invasion process, but these factors need to work in concert for a species to persist or spread in its introduced range. Characteristics such as propagule supply, quality and/or density of propagules, and the dispersal of propagules through an area over time, greatly affects both establishment and successful spread (Ruiz et al. 2000; Casties and Briski 2019). The longer a species persists in a region, the more propagules may be spread, increasing the chances of long-term persistence and of an even greater range in the introduced region (Milbau and Stout 2008).

Anthropogenic alteration of habitat such as subsea structures and shipwrecks serve to connect and extend populations by providing hard substrate in a naturally soft bottom area, enabling sea anemones that inhabit subtidal and deeper depths to extend their range. Offshore petroleum platforms, which rank among the largest artificial structures in the marine environment, are typically placed over soft-sediment substrate that normally would be inhospitable to hard substratedwelling species. These structures provide an artificial reef habitat suitable for attachment, potentially serving as a "stepping stone" for both native and nonnative species (Wolfson et al. 1979; Page et al. 2006): in China, an anemone referred to as Sagartia rosea (an invalid name for the European Sagartia elegans; see Fautin 2016) is a common species on offshore platforms (Yan and Yan 2003; Li et al. 2011), while "Actiniaria" were documented as common on a fixed oil platform in the northern Beibu Gulf of China (Yan 
et al. 2006), and Bunodosoma caissarum Corrêa in Belém, 1987 as common on drilling ships (Ferreira et al. 2006). As these offshore structures may be moved after use, not only do they provide a stepping stone, but they can also introduce a well-established community to a new location.

In the Southern California Bight, M. senile is a common fouling species on oil and gas platforms, with particular dominance in the platform invertebrate assemblages despite its relative rarity in the nearshore environment (Page et al. 2006, 2015). Pipelines in the North Sea cross and intersect a large geographic area, forming a 45,000 km "subway system" of hard substrate habitat across a shelf region characterized by soft sediments. Metridium senile has been noted as occurring on pipelines in the North Sea $(<200 \mathrm{~m})$ and along pipelines $(115 \mathrm{~m}$ ) on the Agulhas Bank at the tip of South Africa, having colonized either through planktonic larval dispersal, dislodgment from ship fouling communities, or by slow movement along the pipeline itself (Laird and Griffiths 2016; Lacey and Hayes 2019). The presence of it on oil rigs in South Africa has encouraged the citation of ship fouling as the most probable vector of introduction (Mead et al. 2011). Although M. senile is not as prevalent south of Massachusetts on the North American Atlantic coast, artificial habitats including the shipwrecks in New Jersey provide fragmented hard substrate habitat that may assist in extending the southward limit of their natural range by increasing habitat availability and complexity.

Both sexual and asexual reproducers are represented in these ten species. Species that solely undergo sexual reproduction include $D$. leucolena and $S$. ornata, while species that are able to undergo both asexual and sexual reproduction include $D$. franciscana, D. lineata, E. pallida, M. senile, N. vectensis and $S$. elegans. Additionally, two species, D. paranaensis and A. alicemartinae, are only known from monosexual populations inferred to solely exhibit asexual reproduction based on the absence of individuals of the opposite sex. Asexual reproduction enables a species to establish potentially long-lived single sex populations with a single inoculation, with population size expanding regardless of the presence of sexual reproduction. The ability to reproduce through both asexual and sexual means in the non-native range, along with the lack of senescence, contributes to a species' ability to be durable invaders (Frank and
Bleakney 1976; Hand and Uhlinger 1992; Stefanik et al. 2013), and those species that are able to reproduce asexually and sexually based on the presence of both sexes are indeed the more widespread of the introduced sea anemones (Figs. 5, 6, and 7).

Of the two modes of reproduction, for anemones, asexual reproduction appears to be the most important in invasion success. For example, although capable of sexual reproduction, D. lineata is regarded as foregoing sexual reproduction throughout its global introduced range (Shick 1976; Shick and Lamb 1977; Minasian and Mariscal 1979; Ting and Geller 2000), although there may potentially be some sexual reproduction (yet to be demonstrated) in regions that have undergone multiple introductions and where male and female anemones occur in the same population (Newcomer et al. 2019; Ryan and Miller 2019). Species may display unique reproductive responses to stress, which shows variation in trade-offs between types of reproduction. Both N. vectensis and M. senile are more likely to undergo asexual and sexual reproduction in favorable conditions than under stress, with the difference in output more pronounced for sexual rather than asexual reproduction (Hand and Uhlinger 1992, Glon et al. 2019). However, the increase in the fission rate of $D$. lineata particularly when temperatures are higher may be more beneficial in increasing the surface area to volume ratio, as there is higher biomass accumulation (Ryan and Miller 2019; Ryan et al. 2019).

Introduced populations that are a single sex (e.g., $D$. lineata, D. paranaensis, $N$. vectensis) can only spread within their introduced habitat by crawling, floating, or rafting. In addition to having limited means of spreading, these populations have limited genetic variation and may be more susceptible to ecological fluctuations. Ephemerality of populations, such as in the case of Sagartia elegans, limits successful establishment; however, multiple introductions, as can occur in a harbor with high shipping activity can increase genotypic variation and may over time lead to establishment and subsequent spread. The limitations of solely asexual reproduction may appear to be a detriment to invasion success, but it may instead create more possibilities. Despite the presence of specialized predators (e.g. the nudibranch Aeolidia sp.) in some introduced areas (Kienberger et al. 2016) the ability to quickly reproduce asexually to form dense clonal groups decreases the impact of predation. 
Furthermore, for numerous introduced species, the reproductive strategies in the introduced range vary from those in the native range, and often manifest as an increase in the frequency of asexual reproduction (Johnson and Shick 1977; Meinesz et al. 1993; Jokela et al. 1997; Alonso and Castro-Díez 2012; KruegerHadfield et al. 2016). This shift towards asexual reproduction in the non-native range has been exploited by numerous species (Platt and Jeschke 2014). The phenomenon may be partially explained by the "invasive queens hypothesis", which postulates that when species are transported to a new environment they are released from their natural enemies, which in turn makes sexual reproduction less advantageous due to its high costs (Platt and Jeschke 2014).

\section{Discussion: assessing the risk of introduction and successful establishment}

Ports with intense shipping routes, particularly longestablished older routes, have the most introduced sea anemones (See Figs. 4, 5, 6, and 7). Such ports can also act as hubs for subsequent introductions (Carlton 2003). All of the Diadumene species discussed here have been introduced to San Francisco Bay, presumably because of the high rates of shipping traffic (and other vectors, such as historical commercial oyster industries) to that bay. The potential risk for ports for the introduction of non-native sea anemones (and other species) can be assessed by examining the salinity, temperature, voyage time, and voyage route, and comparisons of donor and recipient regions (Jóźwiak and Barańska 2014). A longer voyage decreases the potential of a successful introduction, whereas short voyages between harbors may result in more likely introductions (Jóźwiak and Barańska 2014). How a species is able to cope within a stressful environment, even short term, affects how important each of these factors are in determining introduction potential.

Life history traits common among members of lineage may also indicate the potential of successful introductions (Fig. 2). Based on the species that have had successful introductions as compared with those that have remained in their native ranges, the combination of tolerance to environmental extremes with flexibility in reproductive strategy assists in the introduction process. As noted above, the majority of successful introductions are within the Acuticulate group of Metridioidea (Metridium, Diadumene, Sagartia, Exaiptasia), while A. alicemartinae is the only representative of the Actinioidea clade, and $N$. vectensis is the sole representative of the Edwardsioidea. The lineage-specific nature of the primary anemone invaders highlights an ancestral proclivity and rise of traits encouraging survival and thriving after transplantation, suggesting that potential additional invaders may be found within these lineages as global connectivity continues to increase and as the climate and ocean conditions change.

For example, Aiptasiogeton eruptaurantia (Field, 1949), normally ranging from Louisiana to Chesapeake Bay, has now been detected in Rhode Island in both summer 2013 and 2019 surveys, as well as in New York in the summer of 2019 (Wells et al. 2014; J. T. Carlton, M. I. McCuller, and J. Pederson, August 2019 personal observations). This may indicate a potential range expansion. In warm waters, Bartholomea annulata (Le Sueur, 1817), a species native to the Caribbean that undergoes both sexual and asexual reproduction to form aggregations (Jennison 1981), is commonly harvested and thus moved via the aquarium trade (O'Reilly et al. 2018, Legore et al. 2005). The combination of life history strategies encourage the potential for introduction and invasion if released into a non-native body of water from an aquarium. Additionally, the dominant presence of Sagartia "rosea" [= S. elegans, above] in fouling communities on offshore platforms in China (Li et al. 2011) implies that if this is a native member of the Sagartia lineage, it is prime for introduction to new locations.

Several closely related species have been suggested as introduced to other parts of the world, but have not been confirmed, needing further study beyond what is included in this review. Diadumene cincta Stephenson, 1925 has been argued as introduced to Europe, though whether it was an introduction from another continent or a range expansion is unknown (see Hartog and Ates 2011 for full account). In Peru, the presence of another metridioidean, Gonactinia prolifera (Sars, 1835), peaked the interest of Carlgren (1959) as having been introduced from Europe on ships, although this has not been confirmed despite the propensity for asexual reproduction via transverse fission (Stephenson 1935).

Cereus pedunculatus (Pennant, 1777) of the Northeast Atlantic, also a member of the Acuticulate clade 
of anemones, is a temperate, shallow $(<25 \mathrm{~m})$ water species that inhabits sand and mud (Manuel 1981). It is reproductively facile, exhibiting oviparity, or is hermaphroditic or parthenogenetic with prolific viviparity (Stephenson 1929; Rossi 1975; Schäfer 1981; Shick 1991). Although it does employ symbioses with zooxanthellae, it has the potential to acclimate to different environments by being flexible with the specific photosymbiont (Davy et al. 1997). In the family Actiniidae, Actinia equina (Linnaeus, 1758) also reproduces both sexually and asexually (Perrin et al. 1999), prefers rocky substrate, and has a distribution extending across the temperature extremes from the cold northeast Atlantic, northern and southern Africa, Japan, and Israel (Chomsky et al. 2009). It has long proven a taxonomic issue with its high morphological and genetic variability and "cosmopolitan" distribution indicating a species complex (e.g. Monteiro et al. 1997; Chomsky et al. 2009; Wilding and Weedall 2019). Whether the wide, highly variable distribution is indicative of an adaptable lineage is unknown, as it could indicate a potentially successful invader.

Several of these species (D. franciscana, $D$. paranaensis, E. pallida, A. alicemartinae) have unknown or hypothesized native ranges presumably due to understudied research areas or the early nature of their invasion history. Baseline surveys of areas-atrisk are vital, both to understand and record native diversity and to track the spread of non-natives. On the US east coast for example, several collaborative initiatives, such as the Marine Invader Monitoring and Information Collaborative (MIMIC) and New England Rapid Assessment Surveys are undertaking surveys for marine non-natives, focusing on fouling communities where most alien sea anemones have first appeared. These data will be essential moving forward to identify both when and where alien species appear as a first response. In particular, cold polar regions are becoming increasingly vulnerable to introduced species due to rapid effects of climate change and increased boat traffic (e.g. McCarthy et al. 2019; Ware et al. 2015), necessitating routine surveys and identification of potential risk factors.

Our knowledge of sea anemone introductions and invasiveness remains far from complete. Sea anemone biology and life history, including reproductive behavior and dispersal potential, as well as distributions must be further researched particularly in understudied taxa. There are numerous opportunities for molecular studies, from examining the regulation of genes in native and introduced ranges to population genetic diversity and the identification of potential source populations. These investigations can address potential cryptic diversity revealing finer-grained patterns to add to our understanding of invasion patterns across all marine taxa, particularly from a regional perspective. Understanding how life history strategies of sea anemone species and active vectors work together in the twenty-first century will aid in prioritizing survey locations as well as invasions and vector management.

Acknowledgements Graduate student support for Heather Glon was provided by the Ohio State University. We would like to thank Ron Ates for his comments and suggestions while assembling the manuscript. The authors would also like to thank Vreni Häussermann, Alejandro Grajales, Damon Tighe, Sérgio Stamper, and Whitney Leach for use of their photographs and Nuria Clodius, Anna Hopkins, Katherine Newcomer, and Ali Stevens for field and laboratory assistance. We are grateful to our two anonymous reviewers who contributed their expertise and perspective to further improve the manuscript.

\section{References}

Acuña FH, Excoffon AC, Griffiths CL (2004) First record and redescription of the introduced sea anemone Sagartia ornata (Holdsworth, 1855) (Cnidaria: Actiniaria: Sagartiidae) from South Africa. African Zool 7020

Allee WC (1919) Note on animal distribution following a hard winter. Biol Bull 36:96-104

Alonso Á, Castro-Díez P (2012) The exotic aquatic mud snail Potamopyrgus antipodarum (Hydrobiidae, Mollusca): state of the art of a worldwide invasion. Aquat Sci 74:375-383

Anthony KRN, Svane I (1995) Effects of substratum instability on locomotion and pedal laceration in Metridium senile (Anthozoa: Actiniaria). Mar Ecol Prog Ser 124:171-180

Antoniadou C, Chintiroglou C (2007) Zoobenthos associated with the invasive red alga Womersleyella setacea (Rhodomelacea) in the northern Aegean Sea. J Mar Bio Assoc UK 87:629-641

Ardura A, Planes S (2017) Rapid assessment of non-indigenous species in the era of the eDNA barcoding: a Mediterranean case study. Est Coast Shelf Sci 188:81-87

Ates RML, Dekker R, Faasse MA, den Hartog JC (1998) The occurrence of Sagartia elegans (Dalyell, 1848) (Anthozoa: Actiniaria) in the Netherlands. Zool Verh 323:263-276

Bailey SA, Duggan IC, Jenkins PT, MacIsaac HJ (2005) Invertebrate resting stages in residual ballast sediment of transoceanic ships. Can J Fish Aquat Sci 62:1090-1103

Bando KJ (2006) The roles of competition and disturbance in a marine invasion. Biol Invasions 8:755-763 
Batista WR, Fernandes FC, Lopes CC, Lobes RSC, Miller W, Ruiz G (2017) Which ballast water management system will you put aboard? Remnant anxieties: a mini-review. Environments 4:1-12

Bedgood SA, Bracken ME, Ryan WH, Levell ST, Wulff J (2020) Nutritional drivers of adult locomotion and asexual reproduction in a symbiont-hosting sea anemone Exaiptasia diaphana. Mar Bio 167:1-2

Belém MJC, Monteira DC (1977) Contribuições au conhecimento da fauna de cnidários do Rio de Janeiro II. Haliplanella luciae (Verrill, 1898) (Actiniaria, Acontiaria), uma nova ocorréncia no Brasil. Animalia 26:1-19

Bellis ES, Howe DK, Denver DR (2016) Genome-wide polymorphism and signatures of selection in the symbiotic sea anemone Aiptasia. BMC Gen 17:160

Bellis ES, Edlund RB, Berrios HK, Lessios HA, Denver DR (2018) Molecular signatures of host specificity linked to habitat specialization in sea anemones. Eco Evol 8:54135426

Beneti JS, Stampar SN, Maronna MM, Morandini AC, Da Silveira FL (2015) A new species of Diadumene (Actiniaria: Diadumenidae) from the subtropical coast of Brazil. Zootaxa 4021:156-168

Blackburn TM, Pyšek P, Bacher S, Carlton JT, Duncan RP, Vojtēch J, Wilson JRU, Richardson DM (2011) A proposed unified framework for biological invasions. Trends Ecol Evol 26:333-339

Bleakney JS, Meyer KB (1979) Observations on saltmarsh pools, Minas Basin, Nova Scotia 1965-1977. Proc Nova Scotian Inst Sci 29:353-371

Bocharova TM, Kozevich IA (2011) Modes of reproduction in sea anemones (Cnidaria, Anthozoa). Biol Bull 38:849-860

Briski E, Bailey SA, Cristescu ME, MacIsaac HJ (2010) Efficacy of 'saltwater flushing' in protecting the Great Lakes from biological invasions by invertebrate eggs in ships' ballast sediment. Fresh Bio 55:2414-2424

Briski E, Ghabooli S, Bailey SA, MacIsaac HJ (2012) Invasion risk posed by macroinvertebrates transported in ships' ballast tanks. Bio Invasion 14:1843-1850

Briski E, Chan FT, Darling JA, Lauringson V, MacIsaac HJ, Zhan A, Bailey SA (2018) Beyond propagule pressure: importance of selection during the transport stage of biological invasions. Front Ecol Environ 16:345-353

Brock R, Bailey-Brock JH, Goody J (1999) A case study of efficacy of freshwater immersion in controlling introduction of alien marine fouling communities: the USS Missouri. Pacific Sci 53:223

Bryan SE, Cook AG, Evans JP, Hebden K, Hurrey L, Colls P, Jell JS, Weatherley D, Firn J (2012) Rapid, long-distance dispersal by pumice rafting. PLoS One 7

Bucklin A (1982) The annual cycle of sexual reproduction in the sea anemone Metridium senile. Can J Zool 60:3241-3248

Čampara L, Slišković M, Jelić Mrčelić G (2019) Key ballast water management regulations with a view on ballast water management systems type approval process. NAŠE MORE: znanstveno-stručni časopis za more i pomorstvo 66:78-86

Canales-Aguirre CB, Quiñones A, Hernández CE, Neill PE, Brante A (2015) Population genetics of the invasive cryptogenic anemone, Anemonia alicemartinae, along the southeastern Pacific coast. J Sea Res 102:1-9
Canning-Clode J, Fofonoff PW, McCann L, Carlton JT, Ruiz GM (2013) Marine invasions on a subtropical island: fouling studies and new records in a recent marina on Madeira Island (Eastern Atlantic Ocean). Aquat Invasions 8:261-270

Cardeccia A, Marchini A, Occhipinti-Ambrogi A et al (2018) Assessing biological invasions in European Seas: biological traits of the most widespread non-indigenous species. Estuar Coast Shelf Sci 201:17-28

Carl GC, Guiguet CJ (1958) Alien animals in British Columbia, vol 14. British Columbia Provincial Museum, Belleville, 94pp

Carlgren O (1933) Zoantharia and Actiniaria. The Godthaab Expedition 1928. Meddelelser om Gronl 79:1-55

Carlgren O (1959) Corallimorpharia and Actiniaria with description of a new genus and species from Peru. Lunds Universitets Arsskrift 71(6):1-39

Carlton JT (1979a) History, biogeography, and ecology of the introduced marine and estuarine invertebrates of the Pacific Coast of North America. Dissertation, University of California, Davis

Carlton JT (1979b) Introduced invertebrates of San Francisco Bay. In: Conomos TJ (ed) San Francisco Bay: the urbanized estuary. American Association for the Advancement of Science, Pacific Division, San Francisco, pp 427-444

Carlton JT (1996) Pattern, process, and prediction in marine invasion ecology. Biol Conserv 78:97-106

Carlton JT (2003) Community assembly and historical biogeography in the North Atlantic Ocean: the potential role of human-mediated dispersal vectors. Hydrobiologia 503:1-8

Carlton JT (2011) Ch. 3 The inviolate sea? Charles Elton and biological invasions in the world's oceans. In: Fifty years of invasion ecology: the legacy of Charles Elton, 1st edn. Blackwell Publishing, pp 25-33

Carlton JT, Cohen AN (2003) Episodic global dispersal in shallow water marine organisms: the case history of the European Shore Crabs Carcinus maenas and C. aestuarii. J Biogeogr 30:1809-1820

Carlton JT, Eldredge LG (2009) Marine bioinvasions of Hawai'i. The introduced and cryptogenic marine and estuarine animals and plants of the Hawaiian Archipelago. Bishop Museum Bulletins in Cultural and Environmental Studies 4, Bishop Museum Press, Honolulu, 202pp

Carlton JT, Eldredge LG (2015) Update and revision of the marine bioinvasions of Hawai'i: the introduced and cryptogenic marine and estuarine animals and plants of the Hawaiian Archipelago. In: Evenhuis NL, Carlton JT (eds) Lucius G. Eldredge III memorial volume: tribute to a polymath. Bishop Museum Bulletin Zoology, p 9

Carlton JT, Geller JB (1993) Ecological roulette: the global transport of nonindigenous marine organisms. Science 78-82(261):78-82

Carlton JT, Chapman JW, Geller JB, Miller JA, Carlton DA, McCuller MI, Treneman NC, Steves BP, Ruiz GM (2017) Tsunami-driven rafting: transoceanic species dispersal and implications for marine biogeography. Science 357:1402-1406

Carlton JT, Keith I, Ruiz GM (2019) Assessing marine bioinvasions in the Galápagos islands: implications for conservation biology and marine protected areas. Aquat Invasions $14: 1-20$ 
Casties I, Briski E (2019) Life history traits of aquatic nonindigenous species: freshwater vs. marine habitats. Aquat Invasions 14:566-581. https://doi.org/10.3391/ai.2019.14. 4.01

Chomsky O, Douek J, Chadwick NE, Dubinsky Z, Rinkevich B (2009) Biological and population-genetic aspects of the sea anemone Actinia equina (Cnidaria: Anthozoa) along the Mediterranean coast of Israel. J Exp Mar Bio Ecol 375:16-20

Cohen AN, Harris LH, Bingham BL, Carlton JT, Chapman JW, Lambert CC, Lambert G, Ljubenkov JC, Murray SN, Rao LC, Reardon K, Schwindt E (2005) Rapid assessment survey for exotic organisms in southern California bays and harbors, and abundance in port and non-port areas. Biol Invasions 7:995-1002

Cory RL (1967) Epifauna of the Patuxent River Estuary, Maryland, for 1963 and 1964. Chesap Sci 8:71

Coutts ADM, Dodgshun TJ (2007) The nature and extent of organisms in vessel sea-chests: a protected mechanism for marine bioinvasions. Mar Pollut Bull 54:875-886

Coutts ADM, Piola RF, Taylor MD, Hewitt CL, Gardner JPA (2010) The effect of vessel speed on the survivorship of biofouling organisms at different hull locations. Biofouling 26:539-553

Crowell S (1946) A new sea anemone from Woods Hole, Massachusetts. J Wash Acad Sci 36:57-60

Darling JA, Reitzel AR, Finnerty JR (2004) Regional population structure of a widely introduced estuarine invertebrate: nematostella vectensis Stephenson in New England. Mol Ecol 13:2969-2981

Darling JA, Reitzel AR, Burton PM, Mazza ME, Ryan JF, Sullivan JC, Finnerty JR (2005) Rising starlet: the starlet sea anemone, Nematostella vectensis. BioEssays 27:211-221

Darling JA, Kuenzi A, Reitzel AM (2009) Human-mediated transport determines the non-native distribution of the anemone Nematostella vectensis, a dispersal-limited estuarine invertebrate. Mar Eco Prog Ser 380:137-146

Davenport GAC (1903) Variation in the number of stripes on the sea-anemone, Sagartia luciae. Mark Anniv 1903:137-146

Davidson IC, Minton MS, Carney KJ, Miller AW, Ruiz GM (2017) Pioneering patterns of ballast treatment in the emerging era of marine vector management. Mar Policy 78:158-162

Davy SK, Lucas IAN, Turner JR (1997) Uptake and persistence of homologous and heterologous zooxanthellae in the temperate sea anemone Cereus pedunculatus (Pennant). Biol Bull 192:208-216

Den Hartog JC, Ates RML (2011) Actiniaria from Ria de Arosa, Galicia, northwestern Spain, in the Netherlands Centre for Biodiversity Naturalis, Leiden. Zoologische Meded 85:1-44

Dunn DF (1982) Sexual reproduction of two intertidal sea anemones (Coelenterata: Actiniaria) in Malaysia. Biotropica 14:262-271

Escribano-Álvarez P, López-González PJ (2018) Facing the arrival of newcomers: an intertidal sea anemone approach (Hexacorallia, Actiniaria). Bio Invasions 20:2945-2962

Farrapeira CMR, de Melo AVOM, Barbosa DF, da Silva KME (2007) Ship hull fouling in the Port of Recife, Pernambuco. Braz J Ocean 55:207-221
Fautin DG (2016) Catalog to families, genera, and species of orders Actiniaria and Corallimorpharia (Cnidaria: Anthozoa). Zootaxa 4145:1-449

Fautin DG, Hand C (2007) Anthozoa. In: Carlton JT (ed) The light and smith manual: intertidal invertebrates from Central California to Oregon. University of California Press, Berkeley

Ferreira CE, Gonçalves JE, Coutinho R (2006) Ship hulls and oil platforms as potential vectors to marine species introduction. J Coast Res 3:1340-1345

Field L (1949) Sea anemones and corals of Beaufort, N.C. Bull Duke Univ Mar Stn 5:1-39

Floerl O, Pool TK, Inglis GJ (2004) Positive interactions between nonindigenous species facilitate transport by human vectors. Ecol Appl 14:1724-1736

Fofonoff PW, Ruiz GM, Steves B, Simkanin C, Carlton JT (2019a) Diadumene lineata. National Exotic Marine and Estuarine Species Information System. http://invasions.si. edu/nemesis/. Accessed Sept 2019

Fofonoff PW, Ruiz GM, Steves B, Simkanin C, Carlton JT (2019b) Diadumene leucolena. National Exotic Marine and Estuarine Species Information System. http:// invasions.si.edu/nemesis/. Accessed Sept 2019

Fofonoff PW, Ruiz GM, Steves B, Simkanin C, Carlton JT (2019c) Diadumene franciscana. National Exotic Marine and Estuarine Species Information System. http:// invasions.si.edu/nemesis/. Accessed Sept 2019

Frank P, Bleakney JS (1976) Histology and sexual reproduction of the anemone Nematostella vectensis Stephenson 1935. J Nat Hist 10:441-449

Frey MA, Simard N, Robichaud DD, Martin JL, Therriault TW (2014) Fouling around: vessel sea-chests as a vector for the introduction and spread of aquatic invasive species. Manag Biol Invasions 5:21-30

Fukui Y (1991) Embryonic and larval development of the sea anemone Haliplanella lineata from Japan. Hydrobiologia 216:137-142

Gegner HM, Ziegler M, Rädecker N, Buitrago-López C, Aranda M, Voolstra CR (2017) High salinity conveys thermotolerance in the coral model Aiptasia. Bio Open 6:1943-1948

Gemmill JF (1920) The development of the sea-anemones Metridium dianthus (Ellis) and Adamsia palliata. Philos Trans R Soc London Ser B Contain Pap Biol Charact 209:351-375

Glon, H, Costa M, de Lecea A, Goodwin C, Cartwright S, Díaz A, Brickle P, Brewin P (2020) First record of the plumose sea anemone, Metridium senile (Linnaeus, 1761), from the Falkland Islands. BioInv Rec 9: (in press)

Glon H, Haruka Y, Daly M, Nakaoka M (2019) Temperature and salinity survival limits of the fluffy sea anemone, Metridium senile (L.), in Japan. Hydrobiologia 2:303-315

Godwin S, Rodgers K, Jokiel P (2006) Reducing potential impact of invasive marine species in the Northwestern Hawaiian Islands marine national monument. Hawai' 1 Coral Reef Assess Monit Prog (CRAMP) 1:1-66

Goldstein MC, Carson HS, Eriksen M (2014) Relationship of diversity and habitat area in North Pacific plastic-associated rafting communities. Mar Biol 161:1441-1453

Gollasch S, Riemann-Zurneck K (1996) Transoceanic dispersal of benthic macrofauna: Haliplanella luciae (Verrill 1898) (Anthozoa, Actiniaria) found on a ship's hull in a shipyard 
dock in Hamburg Harbour, Germany. Helgoländer Meeresuntersuchungen 50:253-258

Gonzalez-Muñoz R, Simões N, Sanchez-Rodriguez J, Rodriguez E, Segura-Puertas L (2012) First inventory of sea Anemones (Cnidaria: Actiniaria) of the Mexican Caribbean. Zootaxa 3556(1):1

Grajales A, Rodríguez E (2014) Morphological revision of the genus Aiptasia and the family Aiptasiidae (Cnidaria, Actiniaria, Metridioidea). Zootaxa 3826(1):55

Grajales A, Rodríguez E (2016) Elucidating the evolutionary relationships of the Aiptasiidae, a widespread cnidariandinoflagellate model system (Cnidaria: Anthozoa: Actiniaria: Metridioidea). Mol Phylogenet Evol 94:252-263

Grajales A, Rodríguez E (2019) Case 3790: Proposed review of Opinion 2404 and reconsideration of Case 3633: Dysactis pallida Agassiz in Verrill, 1864 (currently Exaiptasia pallida; Cnidaria, Anthozoa, Hexacorallia, Actiniaria): proposed precedence over Exaiptasia diaphana (Rapp, 1829). Bull Zool Nomencl 76:127

Grebelnyi SD, Kovtun OA (2013) A species of sea anemone Sagartia elegans (Dalyell, 1848) (Anthozoa, Actiniaria, Sagartiidae) that is new for the Black Sea and is capable of clonal reproduction. Russ J Mar Biol 39:30-37

Griffiths C, Kruger L, Smith C (1996) First record of the sea anemone Metridium senile from South Africa. S Afri J Zoo 31:157-158

Grizel H, Heral M (1991) Introduction into France of the Japanese oyster (Crassostrea gigas). J Cons Int Explor Mer 47:399-403

Gusmão LC, Grajales A, Rodríguez E (2018) Sea anemones through X-rays: visualization of two species of Diadumene (Cnidaria, Actiniaria) using micro-CT. Am Mus Novit 3907:1-47

Hancock ZB, Goeke JA, Wicksten MK (2017) A sea anemone of many names: a review of the taxonomy and distribution of the invasive actiniarian Diadumene lineata (Diadumenidae), with records of its reappearance on the Texas coast. Zookeys 2017:1-15

Hand C (1956) The sea anemones of Central California. Part III. The acontiarian anemones. Wasmann J Biol 13:189-251

Hand C (1957) Another sea anemone from California and the types of certain Californian anemones. J Wash Acad Sci 47:411-414

Hand C, Uhlinger KR (1992) The culture, sexual and asexual reproduction, and growth of the sea anemone Nematostella vectensis. Biol Bull 182:169-176

Hand C, Uhlinger KR (1994) The unique, widely distributed, Estuarine Sea Anemone, Nematostella vectensis stephenson: a review, new facts, and questions. Estuaries 17:501

Hanzawa N, Gotoh RO, Sekimoto H, Goto T V., Chiba SN, Kuriiwa K, Tamate HB (2012) Genetic diversity and evolution of marine animals isolated in marine lakes. In Caliskan M (ed) Analysis of genetic variation in animals, pp 121-150

Hausman LA (1919) The orange striped anemone (Sagartia luciae, Verrill). An ecological study. Biol Bull 37:363-369

Häussermann V, Försterra G (2001) A new species of sea anemone from Chile, n. sp. (Cnidaria: Anthozoa). An invader or an indicator for environmental change in shallow water? Org Divers Evol 1:211-224
Häussermann V, Försterra G (2005) Distribution patterns of Chilean shallow-water sea anemones (Cnidaria: Anthozoa: Actiniaria, Corallimorpharia), with a discussion of the taxonomic and zoogeographic relationships between the actinofauna of the South East Pacific, the South West Atlantic and the Antarctic. Sci Mar 69:91-102

Häussermann V, Spano C, Thiel M, Lohrmann KB (2015) First record of the sea anemone Diadumene lineata (Verrill, 1869) from the Chilean coast. Spixiana 38:39-42

Hieb K (1977) A population study of the sea anemone Haliplanella luciae in Bodega Harbor. Student Report, Biology of Marine Invertebrates Course. Univ Calif Bodega Mar Lab Bodega Bay CA, 13pp

Hoadley KD, Rollison D, Pettay DT, Warner ME (2015) Differential carbon utilization and asexual reproduction under elevated pCO2 conditions in the model anemone, Exaiptasia pallida, hosting different symbionts. Limnol Oceanogr 60:2108-2120

Hoffmann RJ (1976) Genetics and Asexual Reproduction of the Sea Anemone Metridium senile. Biol Bull 151:478-488

Hoffmann RJ (1986) Variation in contributions of asexual reproduction to the genetic structure of populations of the sea anemone Metridium senile. Evolution 40:357-365

Hoffmann RJ (1987) Short-term stability of genetic structure in populations of sea anemone. Mar Biol 93:499-507

Hunter TT (1984) The energetics of asexual reproduction: pedal laceration in the symbiotic sea anemone Aiptasia pulchella (Carlgren, 1943). J Exp Mar Biol Ecol 83:127-147

Jewett EB, Hines AH, Ruiz GM (2005) Epifaunal disturbance by periodic low levels of dissolved oxygen: native vs. invasive species response. Mar Ecol Prog Ser 304:31-44

Johnson L, Shick JM (1977) Effects of fluctuating temperature and immersion on asexual reproduction in the intertidal sea anemone Haliplanella luciae (Verrill) in laboratory culture. J Exp Mar Biol Ecol 28:141-149

Jokela J, Lively CM, Dybdahl MF, Fox JA (1997) Evidence for a cost of sex in the freshwater snail Potamopyrgus antipodarum. Ecology 78:452-460

Jóźwiak Z, Barańska M (2014) Ecological risk assessment of ballast water. Proc Soc Behav Sci 151:122-126

Jurgens L (2018) Poleward range expansion of a non-indigenous bryozoan and new occurrences of exotic ascidians in southeast Alaska. BioInvasions Rec 7:357-366

Kaluza P, Kölzsch A, Gastner MT, Blasius B (2010) The complex network of global cargo ship movements - supplementary information. J R Soc Interface 7:1093-1103

Kienberger K, Carmona L, Pola M, Padula V, Gosliner TM, Cervera JL (2016) Aeolidia papillosa (Linnaeus, 1761) (Mollusca: Heterobranchia: Nudibranchia), single species or a cryptic species complex? A morphological and molecular study. Zool J Linn Soc 177:481-506

Kiener A (1972) Contribution a l'ecologie, la physiologie et l'ethologie de l'actinie Diadumene luciae (Verrill). Bull Société Zool Fr 96:581-603

Kneib R (1988) Testing for indirect effects of predation in an intertidal soft-bottom community. Ecology 69:1795-1805

Kneib R (1991) Indirect effects in experimental studies of marine soft-sediment communities. Am Zool 31:874-885

Kofoid CA (1915) Marine biology on the pacific coast. In: Grinnell J (ed) Nature and science on the Pacific coast. Paul Elder and Co., San Francisco, p 302 
Konecny C, Harley C (2019) The distribution of the orangestriped green anemone, Diadumene lineata, in relation to environmental factors along coastal British Columbia, Canada. Invasion Biol 138(4):e12268

Krueger-Hadfield SA, Kollars NM, Byers JE, Greig TW, Hammann M, Murray DC, Murren CJ, Strand AE, Terada R, Weinberger F, Sotka EE (2016) Invasion of novel habitats uncouples haplo-diplontic life cycles. Mol Ecol 25:3801-3816

Lacey NC, Hayes P (2019) Epifauna associated with subsea pipelines in the North Sea. ICES J Mar Sci. https://doi.org/ 10.1093/icesjms/fsy196

Laird MC, Griffiths CL (2016) Additions to the South African sea anemone (Cnidaria, Actiniaria) fauna, with expanded distributional ranges for known species. Afr Invertebr 57:15-37

LaJeunesse TC, Parkinson JE, Gabrielson PW, Jeong HJ, Reimer JD, Voolstra CR, Santos SR (2018) Systematic revision of Symbiodiniaceae highlights the antiquity and diversity of coral endosymbionts. Curr Biol 28(16):2570-2580

Layden MJ, Rentzsch F, Röttinger E (2016) The rise of the starlet sea anemone Nematostella vectensis as a model system to investigate development and regeneration. Wiley Interdiscip Rev Dev Biol 5:408-428

Legore RS, Hardin MP, Ter-Ghazaryan D (2005) Organization and operation of the marine ornamental fish and invertebrate export fishery in Puerto Rico. Rev Biol Trop 53:145-153

Li J, Yang T-X, Chen C (2011) A review on biofouling of offshore petroleum facilities. J Sichuan Univ Sci Eng (Nat Sci Ed) 24:321-325

Light SF (1941) Laboratory and field text in invertebrate zoology berkeley. University of California Press, California

Lindsay JA (1975) A salt marsh anemone. Mar Aqua 6:43-48

Lodge DV (1993) Biological invasions: lessons for ecology. Trends Ecol Evol 8:133-137

Lombardi MR, Lesser MP (2010) The annual gametogenic cycle of the sea anemone Metridium senile from the Gulf of Maine. J Exp Mar Bio Ecol 390:58-64

Lopez DN, Arancibia PA, Neill PE (2013) Potential dispersal mechanisms of the cryptogenic anemone, Anemonia alicemartinae. Rev Chil Hist Nat 86:369-372

Ma KCK, Glon HE, Hawk HL, Chapman CN (2020) Reconstructing the distribution of the non-native sea anemone, Diadumene lineata (Actiniaria), in the Canadian Maritimes: local extinction in New Brunswick and no regional range expansion in Nova Scotia since its initial detection. Reg Stud Mar Sci 34:101049

MacGinitie GE (1935) Ecological aspects of a California marine estuary. Am Mid Nat 16:629-765

Maglić L, Frančić V, Zec D, David M (2017) Ballast water sediment management in ports. Mar Pollut Bull. https://doi. org/10.1016/j.marpolbul.2017.09.065

Manuel RL (1981) British anthozoa. Academic Press, London, p 241

Marine Biological Association of the United Kingdom (1957) Plymouth marine fauna, 3rd edn. The Marine Biological Association, Plymouth, p 457

Martin JP, Garese A, Sar A, Acuna FH (2015) Fouling community dominated by Metridium senile (Cnidaria:
Anthozoa: Actiniaria) in Bahia San Julian (southern Patagonia, Argentina). Sci Mar 79:1-20

McCarthy AH, Peck LS, Hughes KA, Aldridge DC (2019) Antarctica: the final frontier for marine biological invasions. Glob Chang Biol 25:2221-2241

McDowell Group (2019) Alaska Visitor Volume Report: Summer 2018, Alaska Department of Commerce, Community, and Economic Development Division of Economic Development

McMurrich J (1904) The Actiniae of the plate collection. Zoologische Jahrbücher Supplementheft 6:215-306

Mead A, Carlton JT, Griffiths CL, Rius M (2011) Introduced and cryptogenic marine and estuarine species of South Africa. J Nat Hist 45:2463-2524

Meinesz A, de Vaugelas J, Hesse B, Mari X (1993) Spread of the introduced tropical green alga Caulerpa taxifolia in northern Mediterranean waters. J Appl Phycol 5:141-147

Milbau A, Stout JC (2008) Factors associated with alien plants transitioning from casual, to naturalized, to invasive. Conserv Biol 22:308-317

Minasian LL Jr, Mariscal RN (1979) Characteristics and regulation of fission activity in clonal cultures of the cosmopolitan sea anemone, Haliplanella luciae (Verrill). Biol Bull 157:478-493

Mito T, Uesugi T (2004) Invasive alien species in Japan: the status quo and the new regulation for prevention of their adverse effects. Glob Environ Res 8:171-193

Miyawaki M (1951) Notes on the effect of low salinity on an Actinian, Diadumene luciae (With 3 Text-figures). J Fac Sci Hokkaido Univ Ser VI Zool 10:123-126

Molina LM, Valiñas MS, Pratolongo PD, Elias R, Perillo GME (2009) First record of the sea anemone Diadumene lineata (Verrill 1871) associated to Spartina alterniflora roots and stems, in marshes at the Bahia Blanca estuary, Argentina. Biol Invasions 11:409-416

Monteiro FA, Solé-Cava AM, Thorpe JP (1997) Extensive genetic divergence between populations of the common intertidal sea anemone Actinia equina from Britain, the Mediterranean and the Cape Verde Islands. Mar Biol 129:425-433

Newcomer K, Flenniken MM, Carlton JT (2019) Home and away and home again: discovery of a native reproductive strategy of the globally invading sea anemone Diadumene lineata (Verrill, 1869) in a satellite population. Biol Invasions 21:1491-1497

O'Reilly E, Titus BM, Nelsen MW, Ratchford S, Chadwick NE (2018) Giant ephemeral anemones? Rapid growth and high mortality of corkscrew sea anemones Bartholomea annulata (Le Sueur, 1817) under variable conditions. J Exp Mar Bio Ecol 509:44-53

Ocaña O, Den Hartog JC (2002) A catalogue of Actiniaria and Corallimorpharia from the Canary Islands and from Madeira, Arquipelago. Life Mar Sci 19A:33-54

Ocaña O, Den Hartog JC, Brito A, Moro L, Herrera R, Martin J, Ramos A, Ballesteros E, Bacallado JJ (2015) A survey of Anthozoa and its habitats along the northwest African coast and some islands: new records, descriptions of new taxa and biogeographical, ecological and taxonomical comments. Part I. Rev Acad Canar Cienc 27:9-66 
Okey TA, Shepherd S, Martínez PC (2003) A new record of anemone barrens in the Galápagos. Noticias de Galápagos $62: 17-20$

Orton JH (1930) Experiments in the sea on the growth-inhibitive and preservative value of poisonous paints and other substances. J Mar Biol Assoc UK 16:373-452

Page HM, Dugan JE, Culver CS, Hoesterey JC (2006) Exotic invertebrate species on offshore oil platforms. Ecol Progr Ser 325:101-107

Page HM, Dugan JE, Miller RJ, Simons R, Viola S (2015) Understanding the role of offshore structures in managing potential Watersipora subtorquata invasions. United States Department of the Interior, Bureau of Ocean Energy Management (BOEM), Pacific OCS Region, OCS Study, BOEM 2019-001, 102pp

Parker GH (1902) Notes on the dispersal of Sagartia luciae Verrill. Am Nat 36:491-493

Patris S, Martin LE, Bell LJ, Dawson MN (2019) Expansion of an introduced sea anemone population, and its associations with native species in a tropical marine lake (Jellyfish Lake, Palau). Fr Biogeol 11:41048

Pearson CVM, Rogers AD, Sheader M (2002) The genetic structure of the rare lagoonal sea anemone, Nematostella vectensis Stephenson (Cnidaria; Anthozoa) in the United Kingdom based on RAPD analysis. Mol Ecol 11:2285-2293

Pederson J, Bullock R, Carlton J, Dijkstra J, Dobroski N, Dyrynda P, Fisher R, Harris L, Hobbs N, Lambert G, Lazowasem E, Mathieson A, Miglietta M, Smith J, Smith III J, Tyrrell M (2005) Marine invaders in the northeast: rapid assessment survey of non-native and native marine species of floating dock communities, August 2003. MIT Sea Grant College Program Publication No. 05-3, Cambridge MA, 40pp

Perrin MC, Thorpe JP, Solé-Cava AM (1999) Actinia equina: a genetic role model and reproductive enigma. Oceanogr Mar Biol Ann Rev 37:129-152

Pierce SK, Minasian LL (1974) Water balance of a euryhaline sea anemone Diadumene leucolena. Comp Biochem Physiol 49:159-167

Pinochet J, Rivera R, Neill PE, Brante A, Hernández CE (2019) Spread of the non-native anemone Anemonia alicemartinae Häussermann \& Försterra, 2001 along the Humboldtcurrent large marine ecosystem: an ecological niche model approach. PeerJ 7:e7156

Platt V, Jeschke JM (2014) Are exotic species red queens? Ethol Ecol Evol 26:101-111

Podbielski I, Bock C, Lenz M, Melzner F (2016) Using the critical salinity $\left(\mathrm{S}_{\text {crit }}\right)$ concept to predict invasion of the anemone Diadumene lineata in the Baltic Sea. Mar Biol 163:227

Posey MH, Hines AH (1991) Complex predator-prey interactions within an estuarine benthic community. Ecology 72:2155-2169

Purcell E (1977) Aggressive function and induced development of catch tentacles in the sea anemone Metridium senile (Coelenterata, Actiniaria). Biol Bull 153:355-368

Purcell E, Kitting C (1982) Intraspecific aggression and population distributions of the sea anemone Metridium senile. Biol Bull 162:345-359
Rädecker N, Raina J-B, Pernice M, Perna G, Guagliardo P, Kilburn MR, Aranda M, Voolstra CR (2018) Using Aiptasia as a model to study metabolic interactions in Cnidarian-Symbiodinium symbioses. Fron Phys 9:214

Rädecker N, Chen JE, Pogoreutz C, Herrera M, Aranda M, Voolstra CR (2019) Nutrient stress arrests tentacle growth in the coral model Aiptasia. Symbiosis 78:61-64

Raghunathan C, Choudhury S (2017) New distributional records of actiniarian sea anemones from Andaman and Nicobar Islands. Rec Zool Surv India 117:26-33

Riemann-Zürneck K (1975) Actiniaria des Südwestatlantik II. Sagartiidae und Metridiidae. Helgolander wiss. Meeresrunters 27:70-95

Riemann-Zürneck K (1986) Zur Biogeographie des Südwestatlantik mit besonderer Berücksichtigung der Seeanemonen (Coelenterata: Actiniaria). Helgoländer Meeresundersuchungen 40:91-149

Ram S (2013) Compositions for control of malicious marine anemones. U.S. Patent No. 8,404,262

Reimer AA (1976) Description of a Tetraclita stalactifera panamensis community on a rocky intertidal Pacific shore of Panama. Mar Biol 35:225-238

Reitzel AM, Darling JA, Sullivan JC, Finnerty JR (2008) Global population genetic structure of the starlet anemone $\mathrm{Ne}$ matostella vectensis: multiple introductions and implications for conservation policy. Biol Invasions 10:1197-1213

Reitzel AM, Chu T, Edquist S, Genovese C, Church C, Tarrant AM, Finnerty JR (2013a) Physiological and developmental responses to temperature by the sea anemone Nematostella vectensis. Mar Ecol Prog Ser 484:115-130

Reitzel AM, Herrera S, Layden MJ, Martindale MQ, Shank TM (2013b) Going where traditional markers have not gone before: utility of and promise for RAD sequencing in marine invertebrate phylogeography and population genomics. Mol Ecol 22:2953-2970

Ringer G (2006) Cruising north to Alaska: the new "gold rush". In: Cruise ship tourism: Issues, Impacts, Cases 270-79

Robertson R (1962) Wentletraps (Epitoniidae) feeding on sea anemones and corals. Proc Malacol Soc Lond 35:51-63

Robinson TB, Swart C (2015) Distribution and impact of the alien anemone Sagartia ornata in the West Coast National Park. KOEDOE 57:1-8

Rodríguez E, Barbeitos M, Daly M, Gusmão LC, Häussermann V, Gusmao LC, Häussermann V (2012) Toward a natural classification: phylogeny of acontiate sea anemones (Cnidaria, Anthozoa, Actiniaria). Cladistics 28:375-392

Rodríguez E, Barbeitos MS, Brugler MR, Crowley LM, Grajales A, Gusmão L, Häussermann V, Reft A, Daly M (2014) Hidden among sea anemones: the first comprehensive phylogenetic reconstruction of the order Actiniaria (Cnidaria, Anthozoa, Hexacorallia) reveals a novel group of hexacorals. PLoS ONE 9:e96998

Rossi L (1975) Sexual races in Cereus pedunculatus (Boad.). Pubbl. Staz. Zool.Napoli (Suppl., VIII Eur. Mar. Biol. Symp.) 39:462-470

Ruiz GM, Carlton JT, Grosholz ED, Hines AH (1997) Global invasions of marine and estuarine habitats by non-indigenous species: mechanisms, extent, and consequences. Am Zool 37:621-632

Ruiz GM, Fofonoff PW, Carlton JT, Wonham MJ, Hines AH (2000) Invasion of coastal marine communities in North 
America: apparent patterns, processes, and biases. Ann Rev Ecol Syst 31:481-531

Ryan WH (2018) Temperature-dependent growth and fission rate plasticity drive seasonal and geographic changes in body size in a clonal sea Anemone. Am Nat 191(2):210-219

Ryan WH, Kubota S (2016) Morphotype distribution of the sea anemone Diadumene lineata in Tanabe Bay, Wakayama; a comparison with Uchida (1936) after 80 years. Publ Seto Mar Biol Lab 44:1-6

Ryan W, Miller T (2019) Reproductive strategy changes across latitude in a clonal sea anemone. Mar Ecol Prog Ser 611:129-141

Ryan W, Adams L, Bonthond G, Mieszkowska N, Pack KE, Krueger-Hadfield SA (2019) Environmental regulation of individual body size contributes to geographic variation in clonal life cycle expression. Mar Bio 166:157

Sassaman C, Mangum CP (1970) Patterns of temperature adaptation in North American Atlantic coastal actinians. Mar Biol 7:123-130

Sassaman C, Mangum CP (1972) Adaptations to environmental oxygen levels in infaunal and epifaunal sea anemones. Biol Bull 143:657-678

Schäfer W (1981) Fortpflanzung und Sexualitāt von Cereus pedunculatus und Actinia equina (Anthozoa, Actiniaria). Helgol. Meeresunters. 34:451-461

Schlesinger A, Kramarsky-Winter E, Rosenfeld H, ArmozaZvoloni R, Loya Y (2010) Sexual plasticity and self-fertilization in the sea anemone Aiptasia diaphana. PLoS ONE. 5

Shaw PW (1991) Effects of asexual reproduction on population structure of Sagartia elegans (Anthozoa: Actiniaria). In: Coelenterate biology: recent research on cnidaria and ctenophora, pp 519-525

Shaw PW, Beardmore JA, Ryland JS (1987) Sagartia troglodytes (Anthozoa: Actiniaria) consists of two species. Mar Ecol 41:21-28

Sheader M, Suwailem AM, Rowe GA (1997) The anemone, Nematostella vectensis, in Britain: considerations for conservation management. Aquat Conserv Mar Freshw Ecosyst 7:13-25

Shick JM (1976) Ecological physiology and genetics of the colonizing actinian Haliplanella luciae. In: Mackie GO (ed) Coelenterate ecology and behavior. Springer, Boston, pp 137-146

Shick JM (1991) A functional biology of sea anemones, 1st edn. Chapman \& Hall, London

Shick JM, Lamb AN (1977) Asexual reproduction and genetic population structure in the colonizing sea anemone Haliplanella luciae. Biol Bull 153:604-617

Shick JM, Hoffmann R, Lamb AN (1979) Asexual reproduction, population structure, and genotype-environment interactions in sea anemones. Am Zool 713:699-713

Shumway SE (1978) Activity and respiration in the anemone, Metridium senile (L.), exposed to salinity fluctuations. J Exp Mar Bio Ecol 33:85-92

Spano CA, Häussermann V, Acuña FH, Griffiths CH, Seeb LW, Gomez-Uchida D (2018) Hierarchical biogeographical processes largely explain the genomic divergence pattern in a species complex of sea anemones (Metridioidea: Sagartiidae: Anthothoe). Mol Phylog Evol 127:217-228
Stefanik DJ, Friedman LE, Finnerty JR (2013) Collecting, rearing, spawning and inducing regeneration of the starlet sea anemone, Nematostella vectensis. Nat Prot 8:916-923

Stephenson TA (1929) On methods of reproduction as specific characters. J Mar Biol Assoc U K 16:131-172

Stephenson TA (1935) The British sea anemones. Volumes I and II. Ray Society, London

Thiel M, Gutow L (2005) The ecology of rafting in the marine environment. II The rafting organisms and community. Oceanogr Mar Biol 43:279-418

Thornhill DJ, Xiang Y, Pettay DT, Zhong M, Santos SR (2013) Population genetic data of a model symbiotic cnidarian system reveal remarkable symbiotic specificity and vectored introductions across ocean basins. Mol Ecol 22:4499-4515

Ting JH, Geller JB (2000) Clonal diversity in introduced populations of an Asian sea anemone in North America. Biol Invasions 2:23-32

Uchida T (1932) Occurrence in Japan of Diadumene luciae, a remarkable actinian of rapid dispersal. J Fac Sci Hokkaido Imp Univ 2:69-82

Uchida H, Soyama I (2001) Sea anemones in Japanese waters. TBS, Japan, p 157

Verrill AE (1865) Classification of Polyps. (Extract condensed from a synopsis of the Polypi of the North Pacific exploring expedition under Captains Ringgold and Rodgers, U.S.N). Ann Mag Nat Hist 5481

Verrill AE (1869) Review of the corals and polyps of the West Coast of America. Trans Connecticut Acad Arts Sci $1: 377-567$

Verrill AE (1898) Descriptions of new American Actinians, with critical notes on other species. Am J Sci 4:493-498

Visscher JP (1928) Nature and extent of fouling of ships' bottoms. Bull US Bur Fish 43, no. 2, Document No. 1031, 193-252

Wahl M (1984) The fluffy sea anemone Metridium senile in periodically oxygen depleted surroundings. Mar Biol 86:81-86

Wahl M (1985) The recolonization potential of Metridium senile in an area previously depopulated by oxygen deficiency. Oecologia 67:255-259

Walsh PJ, Somero GN (1981) Temperature adaptation in seaanemones: physiological and biochemical variability in geographically separate populations of Metridium senile. Mar Biol 62:25-34

Ware C, Berge J, Jelmert A, Olsen SM, Pellissier L, Wisz M, Kriticos D, Semenov G, Kwaśniewski S, Alsos IG (2015) Biological introduction risks from shipping in a warming Arctic. J Appl Ecol 53:340-349

Wasson K, Zabin CJ, Bedinger L, Diaz MC, Pearse JS (2001) Biological invasions of estuaries without international shipping: the importance of intraregional transport. Biol Conserv 102:143-153

Wells C (2013) The failed introduction of the sea anemone Sagartia elegans in Salem Harbor, Massachusetts. Master's Thesis, University of New Hampshire

Wells CD, Harris LG (2019) Out of the blue: the failure of the introduced sea anemone Sagartia elegans (Dalyell, 1848) in Salem Harbor, Massachusetts. Biol Bull 237:283-291

Wells CD, Pappal AL, Cao Y, Carlton JT, Currimjee Z, Jennifer A, Edquist SK, Gittenberger A, Goodnight S, Grady SP, 
Green LA, Harris LG, Harris LH, Hobbs N, Lambert G, Marques AC, Mathieson AC, McCuller MI, Osborne K, Pederson JA, Ros M, Smith JP, Stefaniak LM, Stevens A (2014) Report on the 2013 rapid assessment survey of marine species at New England Bays and Harbors. Office of Coastal Zone Management, Boston, p 26

Wilding CS, Weedall GD (2019) Morphotypes of the common beadlet anemone Actinia equina (L.) are genetically distinct. J Exp Mar Bio Ecol 510:81-85

Williams RB (1975) A redescription of the brackish-water sea anemone Nematostella vectensis Stephenson, with an appraisal of congeneric species. J Nat Hist 9:51-64

Williams RB (1983). Starlet sea anemone: Nematostella vectensis Stephenson,1935. The IUCN Invertebrate Red Data Book 43-46

Williams RB (1987) The current status of the sea anemone Nematostella vectensis in England. Trans Norf Norw Naturalists Soc 27:371-374
Wirtz P (2014) Seven invertebrates new for the marine fauna of Madeira Archipelago. Arquipélago. Life Mar Sci 31

Wolfson A, Van Blaricom G, Davis N, Lewbel GS (1979) The marine life of an offshore oil platform. Mar Ecol Prog Ser 1:81-89

Yan T, Yan WX (2003) Fouling of offshore structures in China: a Review. Biofouling 19:133-138

Yan T, Yan W, Dong Y, Wang H, Yan Y, Liang G (2006) Marine fouling of offshore installations in the northern Beibu Gulf of China. Int Biodeterior Biodegrad 58:99-105 Zabin CJ, Carlton JT, Godwin LS (2004) First report of the Asian sea anemone Diadumene lineata from the Hawaiian Islands. Bishop Museum Occas Pap 79:54-58

Publisher's Note Springer Nature remains neutral with regard to jurisdictional claims in published maps and institutional affiliations. 